NBER WORKING PAPER SERIES

\title{
THE EFFECT OF MACROECONOMIC NEWS ON BELIEFS AND PREFERENCES: EVIDENCE FROM THE OPTIONS MARKET
}

\author{
Alessandro Beber \\ Michael W. Brandt \\ Working Paper 9914 \\ http://www.nber.org/papers/w9914
NATIONAL BUREAU OF ECONOMIC RESEARCH
1050 Massachusetts Avenue
Cambridge, MA 02138

August 2003

We thank Frank de Jong, Joost Driessen, Michael Fleming, Michael Rockinger, Nick Souleles, and seminar participants at the Bank of Italy, ESSEC, St. Anna School of Advanced Studies, University of Amsterdam, Università Bocconi, University of Georgia, University of Lausanne, and University of Reading. We also thank Tim Bollerslev, Jun Cai, and Frank Song for providing some of the announcement data. Financial support from the Alea Research Center at the University of Trento and the Rodney L. White Center for Financial Research at the University of Pennsylvania is gratefully acknowledged. The views expressed herein are those of the authors and not necessarily those of the National Bureau of Economic Research.

(C)2003 by Alessandro Beber and Michael W. Brandt. All rights reserved. Short sections of text, not to exceed two paragraphs, may be quoted without explicit permission provided that full credit, including $\odot$ notice, is given to the source. 
The Effect of Macroeconomic News on Beliefs and Preferences:

Evidence from the Options Market

Alessandro Beber and Michael W. Brandt

NBER Working Paper No. 9914

August 2003

JEL No. G0, G1

\begin{abstract}
We examine the effect of regularly scheduled macroeconomic announcements on the beliefs and preferences of participants in the U.S. Treasury market by comparing the option-implied state-price density (SPD) of bond prices shortly before and after the announcements. We find that the announcements reduce the uncertainty implicit in the second moment of the SPD regardless of the content of the news. The changes in the higher-order moments, in contrast, depend on whether the news is good or bad for economic prospects. Using a standard model for interest rates to disentangle changes in beliefs and changes in preferences, we demonstrate that our results are consistent with time-varying risk aversion in the spirit of habit formation.
\end{abstract}

Alessandro Beber

HEC

University of Lausanne
Michael W. Brandt

Fuqua School of Business

Duke University

134 Towerview Drive

Durham, NC 27708

and NBER

mbrandt@duke.edu 


\section{Introduction}

The market for U.S. Treasury securities is the largest and most active financial market in the world. ${ }^{1}$ Understanding the functioning of this market is therefore of primary importance to academics, policy makers, and practitioners alike. Financial theory predicts that asset prices reflect information about cash-flows and discount rates. In the case of riskfree government bonds, the cash-flows are fixed and the only relevant quantities for pricing are discount rates determined by the general macroeconomic environment. It follows logically that Treasury bond prices should vary with news about macroeconomic indicators. Motivated by this reasoning, a number of recent studies have investigated the response of U.S. Treasury bond prices to regularly scheduled U.S. macroeconomic information releases. The availability of high frequency data has dramatically enhanced detection and estimation of announcement effects in bond prices (e.g., Ederington and Lee, 1993), return volatility (e.g., Bollerslev et al., 2000), and market liquidity (e.g., Fleming and Remolona, 1997, 1999). The results reveal a significant and extremely quick impact of certain announcement types on bond prices accompanied by substantial intradaily fluctuations in volatility and liquidity. All of these studies share an ex-post perspective by describing the realized market dynamics.

Our research takes an ex-ante perspective. We examine the effect of the macroeconomic information releases on the forward-looking beliefs and preferences of participants in the U.S. Treasury market. Specifically, we compare the state-price density (SPD) of bond prices shortly before and after the announcements. The SPD, which can be recovered from option prices, is distinct from the objective probability density function (PDF) because it combines the beliefs of market participants about the likelihood of future states with their preferences toward these states. A high value of the SPD for a particular state indicates that market participants consider the state to be relatively likely to occur, that they dislike the state, or both. The changes in the SPD associated with the macroeconomic announcements can therefore be due to changes in beliefs and/or changes in preferences. The contribution of our paper is to document how the SPD of bond prices changes in response to the information contained in macroeconomic announcements and then to disentangle the two components of the SPD to determine the extent to which changes in the SPD reflect changes in the beliefs or changes in the preferences of market participants.

The design of our analysis is straightforward. We extract SPDs for U.S. Treasury bond futures prices at several times during announcement and non-announcement days using transactions data on options traded on the Chicago Board of Trade (CBOT) over a five-year

\footnotetext{
${ }^{1}$ As of December 2000, the amount of outstanding U.S. Treasury securities privately held was $\$ 2,469$ billion (Source: Treasury Bulletin, December 2000).
} 
sample period. We obtain the SPDs as Edgeworth expansions around log-normal densities, along the lines of Jarrow and Rudd (1982). The results from comparing the SPDs shortly before and after the regularly scheduled information releases are intriguing. We find that the announcements reduce the uncertainty implicit in the second moment of the SPD, regardless of their content. The direction and magnitude of the changes in the higher-order moments of the SPD, in contrast, depend on the information content. The SPD becomes less (more) negatively skewed and less (more) fat-tailed in response to bad (good) news for the bond market. Furthermore, the results are asymmetric, in that bad news have a greater impact on the higher-order moments of the SPD than do good news.

We use a standard jump-diffusion model for the futures price to interpret these results and, more importantly, to disentangle changes in beliefs and in preferences. The effect of the announcements on the second moments of the SPD is consistent with a drop in the jump intensity. The changes in the higher-order moments, however, cannot be attributed to variation in the price process. Instead, we show that the changes in the higher-order moments are consistent with time-varying risk aversion. Bad news for the bond market leads market participants to become less risk averse and for the SPD to be more similar to the PDF. Since bad news for the bond market tends to be good news for economic prospects, this variation in risk aversion is consistent with the intuition underlying habit formation models.

The paper proceeds as follows. In Section 2 we describe the announcements and options data. Section 3 explains our econometric approach for estimating the options-implied SPDs. We present our empirical results in Section 4 and then interpret these results in Section 5. Section 6 concludes with a summary of our findings.

\section{$2 \quad$ Data and Preliminaries}

\subsection{Survey and Announcement Data}

We obtain data on the dates, release times, actual released figures, and median forecasts for the ten most important U.S. macroeconomic information releases from Money Market Services (MMS) covering the period from January 1995 through December 1999. MMS conducts a survey of about 40 money market managers on the Friday of the week before the release of each economic indicator. ${ }^{2}$ MMS reports the median forecast from the survey,

\footnotetext{
${ }^{2}$ The announcement of a given economic indicator typically occurs on the same day of the week and tends to be concentrated in the last two days of the week. Hence, the distance between survey and announcement tends to be the same across announcements. In our sample, the average number of days between survey and announcement is 5.48 with a standard deviation of 1.46 .
} 
which is made available to the market and the business press immediately after the survey is taken. ${ }^{3}$

The set of ten announcements is fairly complete in that it describes: the inflationary process by the consumer price index (CPI) and producer price index (PPI); the situation in the labor market by the civilian unemployment rate (CUR) and non-farm payrolls (NFP); the dynamic of consumption by the retail sales (RS); the state of the economy by the industrial production (IP); the perceived state of the economy by consumer confidence (CC) and the national association of purchasing managers index (NAPM); the conditions of the money market by the Federal Open Market Committee federal funds target rate (FOMC) and the situation in the real estate market by housing starts (HS). Most of these announcements are released widely and virtually instantaneously at a precise scheduled time. The statistical agencies impose lock-up conditions to ensure that the information is not released to the public before the scheduled time (see Fleming and Remolona, 1999). With a few exceptions, the announcements are timed as follows: ${ }^{4}$ six annoucements are at 8:30am ET (CUR, NFP, CPI, HS, PPI, and RS), two are at 10:00am ET (CC and NAPM), and the remaining two announcements are at 09:15am ET (IP) and at 2:15pm ET (FOMC). All of the announcements are monthly, except for the eight FOMC meetings per year. A majority of the announcements occur on a Friday and the employment report (CUR and NFP) is normally the first government incofmation release concerning economic activity in a given month. Table 1 describes in more detail the announcement timing in our sample.

\subsection{Options and Futures Data}

We collect tick-by-tick prices of options written on the U.S. Treasury bond futures. The options are American-style, which means they can be exercised at any time before expiration, and are traded alongside the underlying bond futures contracts at the Chicago Board of Trade (CBOT). The options data covers the same sample period as the announcements data (January 1995 through December 1999). Each data record specifies the option type (call or put), the expiration year and month, the strike price, the date, the time to the nearest second, the exact price, and the type of price (actual trade, reported quote, or nominal price set by the CBOT). In order to have liquid option prices reflecting actual transactions, we exclude quotes and nominal prices. We also exclude transactions that occurred outside

\footnotetext{
${ }^{3}$ Several studies have examined the accuracy of the MMS forecasts. Using a methodology that accounts for potential non-stationarity of the series, we find strong evidence that the MMS median forecast has predictive ability for the actual release. We also find that the median forecast is usually an unbiased predictor.

${ }^{4}$ For instance, in August 1999 the NAPM announcement was released one day before the scheduled date. Moreover, the release time was at 10:45am instead of at 10:00am.
} 
the open outcry time period (before 8:20am or after 3:00pm ET). Finally, we apply the usual data filters to reduce the influence of measurement errors and market microstructure problems (see Hentschel, 2002). The final sample consists of 1,004,068 observations.

We also obtain tick-by-tick prices of the underlying U.S. Treasury bond futures. The bond futures contracts require delivery of a U.S. Treasury bond with 15 or more years to maturity and are the most heavily traded long-term interest rate instruments in the world. The contracts mature in March, June, September, and December. Each data record specifies the time to the nearest second and the exact price of the futures transaction. Given this data, we match every option price with the corresponding prevailing futures price (i.e., the most recent price of the futures contract for the appropriate maturity).

Finally, we use daily U.S. dollar LIBOR rates to proxy for the term structure of riskfree interest rates. We match every option price with the LIBOR rate reported the same trading day for the monthly maturity closest to the expiration date of the option.

\subsection{Implied Volatility Patterns}

It is common to describe the features of options data through the volatility of the underlying security implied by a standard option pricing model, such as that of Black and Scholes (1973). Since we are dealing with American-style options on futures contracts, we use a binomial tree version of the Black (1976) model to compute implied volatilities for each option price. We then sort the options into six moneyness categories (two groups of out-of-the-money options, two groups of in-the-money options and two groups of at-the-money options) and four time to maturity categories (eight to 30 days, 30 to 60 days, 60 to 180 day, and more than 180 days). We define moneyness as:

$$
m=\frac{\ln \left(\frac{K}{F}\right)}{\sigma_{\text {atm }} \sqrt{T-t}},
$$

where $K$ is the strike price, $F$ is the futures price, $\sigma_{\text {atm }}$ is the at-the-money implied volatility and $T-t$ is the time to maturity. This measure of moneyness indicates how many standard deviations the option is in- or out-of-the-money.

Table 2 shows the means and standard deviations of the implied volatilities across the 24 moneyness and time to maturity categories. Comparing options with the same time to maturity but different moneyness, we observe an implied volatility smile with some negative asymmetry. The average implied volatility is higher for far in- and out-of-the money options than for the corresponding at-the-money options (the smile). Furthermore, the average implied volatility is slightly higher for out-of-the-money put options than for 
equally out-of-the-money call options (the negative asymmetry). Comparing at-the-money options with different times to maturity, we also observe a monotonically increasing term structure of average implied volatilities. Both of these patters in the implied volatilities are well summarized in the smoothed implied volatility surface depicted in Figure 1.

Table 2 also shows the number of observations in each category. Using this statistic as indication of liquidity, it is clear that short-dated out- or at-the-money put and call options are the most liquid. Long-dated or in-the-money options are traded much less frequently.

\section{Econometric Approach}

\subsection{Estimation of the SPD}

We infer the SPD from the prices of options with the same time to maturity but different levels of moneyness using the Gram-Charlier expansion approach pioneered by Jarrow and Rudd (1982). However, rather than approximate the density of the price of the underlying security, as they do, we follow Backus et al. (1997) in approximating the density of the log price change. This latter approach leads to a simple characterization of the option prices in terms of the higher-order moments of the distribution of the log price change.

Let the one-period change in the log futures price be:

$$
x_{t+1}=\ln F_{t+1}-\ln F_{t},
$$

where $F_{t}$ is the futures price at date $t$. Over $n$ periods, the log futures price is:

$$
\ln F_{t+n}=\ln F_{t}+\sum_{j=1}^{n} x_{t+j}=\log F_{t}+x_{t+1, t+n},
$$

so that the distribution of $F_{t+n}$ conditional on $F_{t}$ depends on the distribution of the log price change $x_{t+1, t+n}$. The price of a European-style call option on the futures with expiration date $t+n$ and with strike price $K$ is:

$$
C_{t, n, K}=\mathrm{E}_{t}\left[M_{t, t+n}\left(F_{t+n}-K\right)^{+}\right]
$$

where $M_{t, t+n}$ denotes a stochastic discount factor and $x^{+} \equiv \max (0, x)$. Assuming markets are complete, we express, without loss of generality, the stochastic discount factor as a 
function of the futures prices $M_{t, t+n}=M\left(F_{t}, F_{t+n}\right)$. The price of the call option is then:

$$
\begin{aligned}
C_{t, n, K} & =\int_{0}^{\infty} M\left(F_{t}, F_{t+n}\right)\left(F_{t+n}-K\right)^{+} p\left(F_{t}, F_{t+n}\right) d F_{t+n} \\
& =\mathrm{e}^{-r_{n t} n} \int_{0}^{\infty}\left(F_{t+n}-K\right)^{+} q\left(F_{t}, F_{t+n}\right) d F_{t+n}
\end{aligned}
$$

where $p\left(F_{t}, F_{t+n}\right)$ denotes the conditional distribution of the futures price, $q\left(F_{t}, F_{t+n}\right)$ denotes the corresponding risk-neutral distribution defined by the transformation:

$$
q\left(F_{t}, F_{t+n}\right) \equiv \mathrm{e}^{r_{n t} n} M\left(F_{t}, F_{t+n}\right) p\left(F_{t}, F_{t+n}\right),
$$

and $r_{n t}$ is the continuously compounded $n$-period interest rate. Finally, we transform the risk-neutral distribution of the futures price to that of the $n$-period log price change and eliminate the max operator by limiting the range of integration:

$$
C_{t, n, K}=\mathrm{e}^{-r_{n t} n} \int_{\ln \left(K / F_{t}\right)}^{\infty}\left(F_{t} \mathrm{e}^{x_{t+1, t+n}}-K\right) q\left(x_{t+1, t+n}\right) d x_{t+1, t+n} .
$$

The risk-neutral distribution $q(x)$ is the object which we referred to earlier as the SPD. Equation (6) illustrates that the SPD combines the beliefs of market participants about the likelihood of future states, $p\left(F_{t}, F_{t+n}\right)$ in our case, with the preferences of market participants toward these states, as measured by the stochastic discount factor $M\left(F_{t}, F_{t+n}\right)$.

In the special case in which the SPD of the $n$-period log price change is conditionally Gaussian with mean $\mu_{n}$ and standard deviation $\sigma_{n}$, the risk-neutral distribution of $F_{t+n}$ is conditionally log-normal and the solution to equation (7) is the Black (1976) formula:

$$
C_{t, n, K}=\mathrm{e}^{r_{n t} n}\left[F_{t} \mathrm{~N}(d)-K \mathrm{~N}\left(d-\sigma_{n}\right)\right]
$$

where

$$
d=\frac{\ln \left(F_{t} / K\right)+\sigma_{n}^{2} / 2}{\sigma_{n}}
$$

and $\mathrm{N}(x)$ denotes the standard normal cumulative distribution function evaluated at $x$.

In general, the SPD of the log price change can be non-Gaussian. Backus et al. (1997) show that an analytically convenient way to capture the non-normalities of the SPD is through a Gram-Charlier expansion of the SPD around a Gaussian density. Let $x_{t+1, t+n}$ have mean $\mu_{n}$ and standard deviation $\sigma_{n}$ and define the standardized log price change:

$$
\omega_{t+1, t+n}=\frac{x_{t+1, t+n}-\mu_{n}}{\sigma_{n}} .
$$


The Gram-Charlier expansion approach is based on the following fourth-order approximation of the distribution of $\omega$ :

$$
q(\omega)=\varphi(\omega)-\gamma_{1 n} \frac{1}{3 !} D^{3} \varphi(\omega)+\gamma_{2 n} \frac{1}{4 !} D^{4} \varphi(\omega)
$$

where $\varphi(x)$ is the standard normal density evaluated at $x$ and $D^{j}$ denotes the $j$ th derivative operator. Equation (11) serves as an approximation to an arbitrary density with non-zero higher-order moments in which the departures from normality are captured by measures of skewness and kurtosis. Specifically, the cumulant generating function of the Gram-Charlier expansion reveals that the parameters $\gamma_{1 n}$ and $\gamma_{2 n}$ correspond to the standard skewness and excess kurtosis statistics, respectively.

Applying the approximation (11) to the SPD in equation (7), we derive the following expression for the call option price (see the Appendix for details):

$$
\begin{aligned}
C_{t, n, K} \cong & \mathrm{e}^{-r_{n t} n}\left[F_{t} \mathrm{~N}(d)-K \mathrm{~N}\left(d-\sigma_{n}\right)\right] \\
& +F_{t} \mathrm{e}^{-r_{n t} n} \varphi(d) \sigma_{n}\left[\frac{\gamma_{1 n}}{3 !}\left(2 \sigma_{n}-d\right)-\frac{\gamma_{2 n}}{4 !}\left(1-d^{2}+3 d \sigma_{n}-3 \sigma_{n}^{2}\right)\right],
\end{aligned}
$$

where all of the variables are as defined above. Equation (12) expresses the call option price as the Black (1976) formula plus terms involving the skewness and excess kurtosis of the $n$-period change in the log futures price.

The final step of our econometric approach is to estimate the parameters of the GramCharlier expansion of the SPD using prices of options with the same expiration date but with different strike prices. Consider a cross-section of $N$ prices of call options which differ only in their strike prices, $\left\{C_{t, n, K_{1}}, C_{t, n, K_{2}}, \ldots, C_{t, n, K_{N}}\right\}$. We estimate the three parameters $\sigma_{n}, \gamma_{1 n}$, and $\gamma_{2 n}$ by numerically solving the non-linear least-squares (NLLS) problem:

$$
\min _{\sigma_{n}, \gamma_{1 n}, \gamma_{2 n}} \sum_{i=1}^{N}\left[C_{t, n, K_{i}}-C_{t, n, K_{i}}\left(\sigma_{n}, \gamma_{1 n}, \gamma_{2 n}\right)\right]^{2},
$$

where the first option price in the brackets represents the data and the second term is the corresponding theoretical price from equation (12).

\subsection{Extensions}

\subsubsection{Non-Negativity Constraint}

An obvious problem with using polynomial expansions to approximate probability densities is that unconstrained expansions can imply negative probabilities. In the context of Gram- 
Charlier expansions, Jondeau and Rockinger (2001) derive constraints on the skewness and kurtosis parameters in the NLLS problem (13) which guarantee positivity. In addition, they provide a computationally efficient algorithm for solving this constrained problem.

To get a sense for the importance of imposing this positivity constraints in our application, we present in Panel A of Table 3 unconstrained and constrained estimates of the SPD for a randomly selected sub-sample of 3,000 options with 30,60, and 90 days to maturity. For all three maturities, the unconstrained and constrained estimates are identical, which means that the constraint is not binding. At least for this randomly selected sub-sample, the departures from normality implied by our options data are not severe enough to require a positivity constraint on the Gram-Charlier density approximation. Nonetheless, throughout our empirical work we check that the estimated moments of the SPD satisfy the constraints guaranteeing positivity and, in the few cases when they do not, impose the constraints using the algorithm described by Jondeau and Rockinger (2001).

\subsubsection{Implied Volatility Based Estimates}

Backus et al. (1997) suggest a further simplification of the NLLS estimation problem (13). Their approach is based on linearizing the call option price in equation (12) in terms of volatility, which leads to the following implied volatility function:

$$
v_{n}(d) \cong \sigma_{n}\left[1+\frac{\gamma_{1 n}}{3 !}\left(2 \sigma_{n}-d\right)-\frac{\gamma_{2 n}}{4 !}\left(1-d^{2}+3 d \sigma_{n}-3 \sigma_{n}^{2}\right)\right]
$$

where $v_{n}$ is the Black-implied volatility of the option which equates the theoretical price corresponding to the Black (1976) model to the observed price. Using this implied volatility function, Backus et al. estimate the parameters of the Gram-Charlier approximation using the following NLLS estimation problem based on implied volatilities:

$$
\min _{\sigma_{n}, \gamma_{1 n}, \gamma_{2 n}} \sum_{i=1}^{N}\left[v_{n, i}-v_{n}\left(d_{i}\right)\right]^{2} .
$$

This implied volatility based estimator is computationally more efficient than our price based counterpart (13) because it is easier to evaluate the expression (14) than (12).

Panel A of Table 3 shows both price and implied volatility based estimates of the SPD for the random sample of 3,000 option prices described above. The results illustrate clearly that the implied volatility based estimates can be substantially different from the price based estimates. For example, for the 60-day horizon the skewness of the SPD from the price based estimates is -0.182 with a standard error of 0.017 while the volatility based estimates give 
a skewness of 0.065 with a standard error of 0.050. Furthermore, judging by the standard errors in parentheses, the implied volatility based estimates are all approximately half as precise as the corresponding price based estimates. This observation is consistent with the finding of Christoffersen and Jacobs (2002) that implied volatility based estimates of option pricing models are substantially more noisy than price based estimates. Because of this greater imprecision of the implied volatility based estimates and because it is unclear how accurate the linearization of the option price underlying equation (14) is in our context, we use price based estimates of the SPD throughout our empirical work.

\subsubsection{Early Exercise of American-Style Options}

Our econometric approach treats the options as if they are European-style although in actuality we are dealing with American-style options. Following Melick and Thomas (1997), we incorporate the early exercise feature by expressing the values of the American-style call and put options as convex combinations of upper and lower bounds:

$$
\begin{aligned}
& C_{t, n, K}^{*} \cong \lambda_{n, K}^{c} C_{t, n, K}^{u}+\left(1-\lambda_{n, K}^{c}\right) C_{t, n, K}^{l} \\
& P_{t, n, K}^{*} \cong \lambda_{n, K}^{p} P_{t, n, K}^{u}+\left(1-\lambda_{n, K}^{p}\right) P_{t, n, K}^{l}
\end{aligned}
$$

with

$$
\begin{aligned}
C_{t, n, K}^{u} & =\mathrm{E}_{t}\left[\max \left(0,\left(F_{t+n}-K\right)\right)\right] \\
C_{t, n, K}^{l} & =\max \left(\mathrm{E}_{t}\left[F_{t+n}\right]-K, e^{-r_{n t} n} \mathrm{E}_{t}\left[\max \left(0,\left(F_{t+n}-K\right)\right)\right]\right) \\
P_{t, n, K}^{u} & =\mathrm{E}_{t}\left[\max \left(0,\left(K-F_{t+n}\right)\right)\right] \\
P_{t, n, K}^{l} & =\max \left(K-\mathrm{E}_{t}\left[F_{t+n}\right], e^{-r_{n t} n} \mathrm{E}_{t}\left[\max \left(0,\left(K-F_{t+n}\right)\right)\right]\right) .
\end{aligned}
$$

The lower bound is the European-style option price and the upper bound is derived in Chaudhary and Wei (1994). Applying the Gram-Charlier approximation (11) to the SPDs embedded in equation (17), we can derive analytic expressions for the upper and lower bounds (see the Appendix for details). Notice that for out-of-the-money options the upper and lower bounds differ only by the discount factor and their spread is therefore very tight, especially when interest rates are low and the maturity date is near. In fact, the maximum relative difference between the upper and lower bounds for our sample of options is only 0.59 percent, which suggests already that the early exercise feature is negligible.

To incorporate these bounds into our econometric approach, we assume that the parameters $\lambda_{n, K}^{c}$ and $\lambda_{n, K}^{p}$ are the same for all options with a given maturity. We then 
include this single parameter $\lambda_{n}$ in the NLLS problem: ${ }^{5}$

$$
\min _{\sigma_{n}, \gamma_{1 n}, \gamma_{2 n}, \lambda_{n}} \sum_{i=1}^{N} \sum_{j=1}^{M}\left(\left(C_{t, n, K_{i}}-C_{t, n, K_{i}}^{*}(.)\right)^{2}+\left(P_{t, n, K_{j}}-P_{t, n, K_{j}}^{*}(.)\right)^{2}\right)
$$

where $C_{t, n, K}^{*}$ and $P_{t, n, K}^{*}$ are the American-style option prices in equation (16).

Panel B of Table 3 compares estimates of $\sigma, \gamma_{1}$, and $\gamma_{2}$ obtained from the estimators (13), which treats the options as European-style, and (18), which explicitly incorporates the early exercise feature, for the random sample of 3,000 option prices described above. The results are strikingly similar. Even at the 60-day horizon, for which the differences in the estimates are most pronounced, the skewness and kurtosis of the SPD from the two estimators are well within two standard errors of each other. Furthermore, the estimates of the parameter $\lambda_{n}$ are always less than 1/1000 in magnitude and are statistically indistinguishable from zero. This implies that the option price is essentially determined by the lower bound, the European-style price, which is consistent with the options normally being exercised at maturity. Indeed, the actual exercise data for our sample periods reveals that 83 percent the exercises occurred at the expiration date and more than 90 percent occurred in the week prior to the expiration date. Because of these findings and because the estimator (13) is easier to implement (it involves the computation of only one option price as opposed to two), we pretend as if the options are European-style throughout our empirical work.

\section{Empirical Results}

\subsection{Seasonality and Time Horizon}

Before we can study the effects of the macroeconomic announcements on the SPD, we first need to address two issues which arise in this analysis: the possibility of intra-weekly and intra-daily seasonalities of the SPD and the dependence of the SPD on the time horizon.

We first compare the average at-the-money implied volatility and the moments of the option-implied SPD on announcement and non-announcement days for different days of the week and times of the day. We compute the at-the-money implied volatility by inverting a binomial tree version of the Black (1976) formula for options with moneyness $m$ between -0.5 and 0.5. We estimate the moments of the SPD through the NLLS estimator (13). In both cases, we use the most liquid cross-section of options with eight to 44 days to maturity.

\footnotetext{
${ }^{5}$ We also considered specifications with separate parameters for call and put options as well as with parameterizations of $\lambda_{n}$ as a function of the strike price. The results are qualitatively the same.
} 
The first plot in the first row of Figure 2 shows that if we consider only days during which at least one of the ten announcements occurs, the at-the-money implied volatility and the second moment of the option-implied SPD exhibit a similar decreasing pattern, with Mondays displaying the highest value and Fridays the lowest. Mondays and Fridays are the days with the least and most announcements, respectively (28 versus 207 releases), suggesting that the announcements reduce the uncertainty implicit in both the at-the-money implied volatility and the second moment of the SPD. ${ }^{6}$ In contrast, the higher-order moments of the SPD do not exhibit such a pattern. The second plot in the first row demonstrates that the day-of-the-week effects in the at-the-money implied volatility and the second moment of the SPD are specific to the announcement days. If we consider only non-announcement days, these two uncertainty measures are virtually constant throughout the week. There is a slight increase in uncertainty on Thursdays, the most frequent pre-announcement day, which is consistent with uncertainty being greatest just prior to the announcements.

The second row of Figure 2 plots the at-the-money implied volatility and moments of the SPD at different times during the day. The first plot for announcement days shows that uncertainty is decreasing substantially throughout the day. The largest drop occurs after 8:30am, which corresponds to the time at which most of the announcements occur. In contrast, the higher-order moments of the SPD are again constant throughout the day. The second plot of the second row shows that on non-announcement days there are two much smaller decreases in uncertainty at the beginning and at the end of the trading day, which may be attributable to the opening and closing of daily positions.

We conclude from Figure 2 that the SPD exhibits no apparent intra-weekly and intradaily seasonalities other than the ones associated with the announcements. This conclusion implies that there is no need to control for the day of the week and time of the day in our empirical work. Furthermore, the day-of-the-week and time-of-the-day effects observed on announcement days foreshadow some of our empirical results in the next section.

Another issue which arises in our empirical work is the varying time horizon of the SPD. Since we are using exchange-traded options with specific expiration dates, the horizon of the option-implied SPD varies in a sawtooth-like fashion throughout the sample. Due to the regularity of both the expiration and announcement calendars, certain announcements tend to be released just days before the next expiration date while others are typically released shortly after an expiration and hence about a month before the following expiration date. To

\footnotetext{
${ }^{6}$ Ederington and Lee (1996) document a similar day-of-the-week effect in the at-the-money implied volatility of options on Treasury bond futures for a different sample period (1988-1992).
} 
the extent that the non-normalities of the SPD depend on the time horizon, this correlation between the announcement and expiration dates may lead to difficulties in comparing the results across the different announcement types.

We mitigate this problem in two ways. First, we concentrate on the cross-section of options with the shortest maturity between eight and 44 days. ${ }^{7}$ These short-term options are the most liquid. Furthermore, it is reasonable to expect that the effect of the announcements is most pronounced for short horizons that do not cover another information release of the same type. ${ }^{8}$ Second, we include the time to maturity as an explanatory variable in each of the following empirical specifications. If an announcement has a different effect at different horizons, this will be reflected in the time variable and the effect of an announcement release can therefore be disentangled from the effect of the time to maturity.

\subsection{Unconditional Response of the SPD}

We first study the unconditional response of the SPD to the macroeconomic announcements without considering whether an announcement is "good" or "bad" news. We examine the changes in both the average at-the-money implied volatility and the moments of the fitted SPD at the daily and intra-daily frequency. For the daily analysis, we construct daily timeseries of the average at-the-money implied volatility and moments of the fitted SPD using all transactions of the shortest maturity options available each day. ${ }^{9}$ Given dummy variables $D_{k t}$, where $D_{k t}=1$ if announcement $k$ is made on day $t$ and $D_{k t}=0$ otherwise, we estimate the following regression:

$$
\left(\mu_{t}-\mu_{t-1}\right)=\alpha_{t}+\sum_{k=1}^{9} \beta_{k t} D_{k t}+\gamma_{t} T+e_{t},
$$

where $T$ is the time to maturity of the option and $\mu_{t}-\mu_{t-1}$ represents the day-to-day change in either the average at-the-money implied volatility or in the standard deviation $\sigma_{n}$, absolute value of skewness abs $\left(\gamma_{1 n}\right)$, or excess kurtosis $\gamma_{2 n}$ of the fitted SPD.

Although we include all ten announcements in the regression, we only present and discuss here the results for the CPI, Employment Report (ER), and PPI announcements. Ederington and Lee (1993) and Bollerslev et al. (2000) document that these three announcement types are by far the most influential for Treasury returns and their volatility. The results for the

\footnotetext{
${ }^{7}$ It is common to ignore options with less than a week to expiration due to market microstructure issues.

${ }^{8}$ Consistent with this argument, the results for medium- and long-term options are qualitatively the same, but less pronounced than for short-term options. The results for longer horizons are available on request.

${ }^{9}$ Since most announcements take place at 8:30am ET, we exclude the first ten minutes of trading to sharpen the distinction between announcement and non-announcement days.
} 
other announcements, which we include in the regression mostly to disentangle the effects of concurrent announcements, are weaker but qualitatively similar.

Panel A of Table 4 shows that almost one third of the variance of the day-to-day changes in the average at-the-money implied volatility is attributable to the announcements. All coefficients are highly significant with negative signs, consistent with the intuition that the announcements reduce uncertainty. The strongest effect is registered for the employment report with an average drop in the at-the-money implied volatility of 0.85 percent.

It is possible that the response of the at-the-money implied volatility masks changes in the higher-order moments of the SPD. However, Panel B of Table 4 shows that this is not the case in general. The skewness and excess kurtosis of the option-implied SPD are not systematically affected by the event of an announcement. Even considering the absolute value of skewness, a more uncertainty-related measure, we obtain just a ten percent significance level for the employment report. We conclude from these results that the unconditional reduction in uncertainty is almost completely exerted on the second moment.

To further sharpen this analysis, we examine next the intra-day changes of the at-themoney implied volatility and moments of the fitted SPD surrounding the macroeconomic announcements. For this, we replace the daily changes $\mu_{t}-\mu_{t-1}$ in equation (19) with intradaily changes $\mu_{\text {post }}-\mu_{\text {pre }}$, where the pre and post statistics are computed using all transaction during the 45 minutes preceding and following the typical release time, respectively. In the case of the early 8:30am announcements, the pre interval is $2: 15$ to $3: 00 \mathrm{pm}$ of the prior day since the market opens only at 8:20am.

Panel A of Table 5 shows that the at-the-money implied volatility drops significantly during the 45 minutes after the CPI, ER, and PPI releases. This indicates a very quick reaction of the SPD to the announcements, consistent with the results of Fleming and Remolona (1999) and Bollerslev et al. (2000) for bond returns and their realized volatility, respectively. Moreover, comparing the intra-daily results to the corresponding daily results in Panel A of Table 4 reveals that the drop in implied volatility is not transitory. The 45-minute change does not seem to revert over the remainder of the day. The differences between the daily and intra-daily coefficient are greatest for the PPI release. This is consistent with the PPI often being released the day before the CPI, so that the afternoon of the PPI release is the pre-annoucement period of the CPI release. ${ }^{10}$ Finally, Panel B of Table 5 shows that the results for the at-the-money implied volatility relates directly to the second moment of the SPD. The higher-order moments of the fitted SPD are again unaffected.

\footnotetext{
${ }^{10}$ The PPI is released the day before the CPI about 40 percent of the times in our five-year sample.
} 


\subsection{Conditional Response of the SPD}

We now turn to the conditional effect of the macroeconomic announcements on the SPD, where we condition our previous analysis on the content of the news. To gauge the extent to which an announcement contains new information, we construct the following standardized measure of surprise:

$$
S_{k}=\frac{A_{k}-X_{k}}{\sigma_{k}}
$$

where $A_{k}$ is the value of the main statistic released in announcement $k, X_{k}$ denotes the corresponding median survey forecast, and $\sigma_{k}$ is the empirical standard deviation of the innovations $A_{k}-X_{k}$. Standardizing the surprise by $\sigma_{k}$ allows us to compare the regression coefficients across different announcement types. We then estimate for each announcement type the following regression:

$$
\left(\mu_{t}-\mu_{t-1}\right)=\alpha_{k}+\beta_{k} S_{k}+\sum_{h=1}^{H} \delta_{h} S_{h}+\gamma_{k} T+e_{k},
$$

where $\mu_{t}-\mu_{t-1}$ represents again the day-to-day change in either the average at-the-money implied volatility or in the standard deviation $\sigma_{n}$, skewness $\gamma_{1 n}$ (signed here), or excess kurtosis $\gamma_{2 n}$ of the fitted SPD. The subscript $h$ refers to announcements which are released concurrently with announcement $k .{ }^{11}$ Including the terms subscribed by $h$ in the regression serves to isolate the marginal effect of each announcement type.

Table 6 presents the regression results for the CPI, NFP and PPI announcements. Panel A shows again that the event of an announcement leads to a drop in the at-the-money implied volatility. The intercepts of the regressions are all negative and statistically significant at the one-percent level. However, the information content appears irrelevant for this drop in implied volatility. The slope coefficients are insignificant in all cases and the adjusted $R^{2}$ are substantially lower than in Panel A of Table 4.

The results for the standard deviation of the SPD in Panel B of Table 6 are qualitatively the same as for the implied volatility. The standard deviation drops after an announcement irrespective of the information content. However, the results for higher-order moments of the SPD are very different. A positive (negative) surprise in the CPI release does not affect the standard deviation of the SPD, but significantly increases (decreases) its skewness and decreases (increases) its excess kurtosis. This pattern in the coefficients is the same for the NFP announcement, although the significance levels are lower.

\footnotetext{
${ }^{11}$ For the announcements considered here, CUR and NFP are always released jointly in the Employment Report. The CPI and PPI are occasionally released together with RS. Table 1 summarizes the number of concurrent announcements in our sample.
} 
Given that the SPD is on average negatively skewed on both announcement and nonannouncement days (see Figure 2), we can interpret these findings as follows. A positive surprise results in a SPD which is closer to being Gaussian, with less negative skewness and less excess kurtosis. The opposite is true for a negative surprise. To better understand this pattern, we classify surprises as being good (bad) news for the Treasury market depending on whether the surprise is on average positively (negatively) correlated with bond returns over the 30 minutes following the announcement. For all of the announcements except the CUR, a positive (negative) surprise corresponds to bad (good) news, consistent with the literature (e.g., Edison, 1996). Therefore, bad news for Treasuries leads to a more Gaussian SPD. We will return to the broader economic significance of this finding below.

We further examine whether the announcement effects vary with the sign of the surprise. For this, we generalize equation (21) by allowing for different slope coefficients depending on the good and bad news as follows:

$$
\left(\mu_{t}-\mu_{t-1}\right)=\alpha_{k}+\left\{\begin{array}{c}
\beta_{G k}\left|S_{k}\right| \\
\beta_{B k}\left|S_{k}\right|
\end{array}+\sum_{h=1}^{H}\left\{\begin{array}{c}
\delta_{G h}\left|S_{h}\right| \\
\delta_{B h}\left|S_{h}\right|
\end{array}+\gamma_{k} T+e_{k}\right.\right.
$$

where the subscripts $G$ and $B$ indicate whether an announcement is good or bad.

Table 7 presents the results for this specification. Panel A shows that the announcement related drop in the at-the-money implied volatility documented in the previous tables depends to some extent on the information content of the announcement. For both the CPI and NFP annoucements, the slope coefficients are significantly positive, which, together with the negative intercepts, means that the at-the-money implied volatility drops comparatively less when these announcements contain bad news. However, Panel B of Table 7 reveals that this asymmetry in the at-the-money implied volatility response is actually an artifact of asymmetric responses of the higher-order moments of the SPD, rather than due to an asymmetric change in uncertainty. The slope coefficients for the standard deviation of the SPD are insignificant in almost all cases, while we observe a significant increase in the skewness of the SPD after CPI and NFP bad news and a significant reduction in the excess kurtosis of the SPD after CPI, NFP, and PPI bad news. We conclude from these results that the response of the SPD to the announcements is mostly driven by bad news. ${ }^{12}$

In tables 8 and 9 we repeat the conditional analysis above for intra-day changes in the

\footnotetext{
${ }^{12}$ Since we use the absolute value of the surprise in this specification, the asymmetric pattern depends on our definition of good or bad news as well as on the magnitude of the surprise. We verified for all of the announcements that a dummy variable for good or bad news alone is never significant. The magnitude of the surprise is thus important in determining the change in the higher-order moments of the SPD. The results are qualitatively similar if we use the squared surprise instead of its absolute value.
} 
at-the-money implied volatility and moments of the option-implied SPD. The results confirm that the information content of the announcement plays a negligible role for changes in the at-the-money implied volatility, with the exception of bad NFP news (Panel A of tables 8 and 9). The tables also support our previous finding that positive (negative) CPI, NFP, and PPI surprises lead to a reduction (increase) in the negative skewness and excess kurtosis of the SPD (Panel B of Table 8). Furthermore, the explanatory power is again considerably enhanced by differentiating between the effects of good and bad news, in which case only the effect of bad news remains highly significant (Panel B of Table 9).

We conclude this section with a test of the predictive ability of the SPD. Specifically, we examine whether the moments of the SPD estimated shortly before an announcement help predict the announcement surprise relative to the MMS survey forecasts. The results are unimpressive and hence not tabulated here. Consistent with the MMS forecasts being unbiased and efficient, the moments of the SPD do not help predict the magnitude or absolute value of the surprise. There is some marginal statistical evidence of the higher order moments of the SPD being able to predict the sign of the surprise in a multinomial logit specification, but the magnitude of this effect is small in an economic sense.

\section{Changing Beliefs or Changing Preferences?}

Having documented systematic changes in the option-implied SPD in response to major macroeconomic announcements, we now turn to an interpretation of our empirical results with the specific aim to disentangle changes in the beliefs and changes in the preferences of market participants. We first interpret our results in the context of a stylized jump-diffusion model and then show that this interpretation also holds in a far less structural setting.

\section{$5.1 \quad$ Jump-Diffusion Model}

The sharpest price changes of U.S. Treasuries tend to be associated with macroeconomic announcements and occur within a few minutes of the news (Fleming and Remolona, 1997). It is therefore sensible to assume that bond futures prices follow a jump-diffusion process:

$$
\frac{d F}{F}=(\mu-\lambda \bar{k}) d t+\sigma d Z+k d q
$$

where $F$ denotes the futures price, $\sigma$ is the instantaneous volatility of futures returns in the absence of jumps, $Z$ is a standard Wiener process, $k$ measures the magnitude of percentage price jumps and is distributed as $\ln (1+k) \sim \mathrm{N}\left[\mu_{J}-\frac{1}{2} \sigma_{J}^{2}, \sigma_{J}^{2}\right], \bar{k}$ denotes the average percentage 
price jump $\exp \left(\mu_{J}\right)-1$, and $q$ is a Poisson counter with instantaneous intensity $\lambda$ such that $\operatorname{Prob}[d q=1]=\lambda d t$. Under this model, the futures prices follows a geometric Brownian motion most of the time, except when, an average of $\lambda$ times per year, the price jumps discretely by a random percentage $k$. Notice that although we know the timing of the announcements, we make the standard assumption of random Poisson jump arrivals as opposed to using a deterministic jump process. The reason is that we do not know if a specific announcement induces a jump and, more importantly, there are a number of instances in which bond prices appear to have jumped on non-announcement days.

Following the approach of Naik and Lee (1990), we use an equilibrium pricing kernel to obtain the risk-neutral price dynamics:

$$
\frac{d F}{F}=\left(c-\lambda^{*} \bar{k}^{*}\right) d t+\sigma d Z+k^{*} d q^{*}
$$

where $c$ is the cost of carry of the asset (zero for futures), $k^{*}$ measures the magnitude of risk-neutral percentage price jumps and is distributed as $\ln \left(1+k^{*}\right) \sim \mathrm{N}\left[\mu_{J}^{*}-\frac{1}{2} \sigma_{J}^{2}, \sigma_{J}^{2}\right], \bar{k}^{*}$ denotes the risk-neutral average percentage price jump $\exp \left(\mu_{J}^{*}\right)-1$, and $q^{*}$ is a Poisson counter with risk neutral instantaneous intensity $\lambda^{*}$. Naik and Lee show that when there exists a representative agent maximizing a utility function with constant relative risk aversion $\Gamma$, the relationship between the risk-neutral parameters to their physical counterparts is:

$$
\begin{gathered}
\lambda^{*}=\lambda \exp \left[-\Gamma \mu_{J}+0.5 \sigma_{J}^{2}\left(\Gamma^{2}+\Gamma\right)\right] \\
\mu_{J}^{*}=\mu_{J}-\Gamma \sigma_{J}^{2}
\end{gathered}
$$

Pricing European-style option with these risk-neutral price dynamics is straightforward (e.g., Merton, 1976). Specifically, the price of a call option with strike price $K$ and time to expiration $T$ is:

$$
C=\exp (-r T) \exp \left(-\lambda^{*} T\right) \sum_{j=0}^{\infty} \frac{\left(\lambda^{*} T\right)^{j}}{j !} B L_{j},
$$

where for $j=0,1, \ldots$ jumps, we have:

$$
B L_{j}=F \exp \left(r_{j} T\right) \mathrm{N}\left[d_{j}\right]-K \mathrm{~N}\left[d_{j}-\sigma_{j} T\right]
$$


with

$$
\begin{aligned}
r_{j} & =-\lambda^{*} \bar{k}^{*}+\frac{j \mu_{J}^{*}}{T} \\
\sigma_{j}^{2} & =\sigma^{2}+\frac{j \sigma_{J}^{2}}{T} \\
d_{j} & =\frac{\ln (F / K)+T\left(r_{j}+0.5 \sigma_{j}^{2}\right)}{\sigma_{j} \sqrt{T}} .
\end{aligned}
$$

To interpret our empirical results in the context of this jump-diffusion framework, we need to calibrate the parameters of the model to our data. For this, we simply classify as jumps the 25 largest absolute price changes or equivalently the 98 percentile of the empirical absolute return distribution. This classification corresponds approximately to a physical jump intensity of $\lambda=5$. It results in an estimate of the physical mean jump size $\bar{k}$ that is not significantly different from zero and an estimate of the physical jump volatility $\sigma_{J}$ of two percent. We then set the variance of the diffusion to be the difference between the sample variance of daily returns and the variance induced by the jumps, or $\sigma^{2}=\sigma_{j}^{2}-\left(j \sigma_{J}^{2}\right) / T$. Finally, we let risk aversion $\Gamma$ range from zero to 15.

An intuitive way to check that this calibration is sensible is to compare the SPD implied by the model to our empirical estimates. We use the calibrated model to simulate a set of option prices for levels of moneyness, time to maturity, and a risk-free rate which match the average features of our sample. We then fit a Gram-Charlier expansion of the SPD to this simulated data and compare the results to our empirical estimates. The general conclusion from this exercise is that, with risk aversion of $\Gamma=5$, the SDPs implied by our calibrated model are very similar to our empirical estimates.

Figure 3 presents the key insights from this jump-diffusion model. The first plot illustrates the effects of a reduction in the physical jump intensity from $\lambda=5$ to $\lambda=4$ on the implied volatilities of options with different moneyness. The at-the-money implied volatility drops substantially. The shape of the smile, however, is more or less unchanged, suggesting that the higher order moments of the SPD are unaffected. The second plot shows the effects of a reduction in risk aversion from $\Gamma=10$ to $\Gamma=1$. In striking contrast to the first plot, the at-the-money implied volatility remains constant but the smile becomes more symmetric and less pronounced, implying a less negatively skewed and less fat-tailed SPD. The third plot confirms this relationship between risk aversion and the higher-order moments of the SPD. It shows that, as $\Gamma$ drops from 15 to zero, the negative skewness of the SPD decreases from -0.31 to -0.01 and the excess kurtosis decreases from 1.18 to 1.05 . 
In the context of our empirical results, each announcement is likely to be associated with a perceived reduction in the physical jump intensity $\lambda$. Since we are considering fairly shortterm options and since macroeconomic announcements are the most likely cause of jumps, having one less announcement until a given option matures is analogous to having a lower jump intensity (for the purpose of pricing that particular option). The first plot in Figure 3 shows that such reduction in the jump intensity produces a drop in uncertainty but leaves the higher-order moments of the SPD largely unchanged. ${ }^{13}$ This reasoning is consistent with our observation in Table 4, that the event of an announcement is associated with a drop in the subsequent uncertainty, measured either by the implied volatility or standard deviation of the SPD, but is not related to changes in the higher-order moments of the SPD.

It is much more difficult to explain the results in the remaining tables with a perceived change in the physical price process. Recall our most striking result is that bad news leads to a less negatively skewed and also less fat-tailed SPD. In the jump-diffusion model above, the higher-order moments of the physical return distribution are mostly controlled by the parameters $\mu_{J}$ and $\sigma_{J}$. To be consistent with our empirical results, bad news, which is likely to be associated with a negative jump in the futures price, would have to lead to an increase in $\mu_{J}$, so future jumps are less negative on average, as well as a drop in $\sigma_{J}$, causing future jumps to also be less volatile. It is difficult, at least for us, to think of an economic or statistical explanation for such change in the physical price process.

The results for the higher-order moments are instead more consistent with a change in risk aversion. As the second and third plots of Figure 3 illustrate, a drop in risk aversion has little effect on the standard deviation of the SPD but results in less negative skewness as well as less excess kurtosis. To explain the results with a change in risk aversion, bad news for bonds must lead a decrease in risk aversion and vice versa for good news, although to a lesser extent. Such correlation between macroeconomic announcements and risk aversion is consistent with economic intuition because bad news for bonds tends to be good news for economic prospects. Therefore, risk aversion decreases when consumers receive good news for economic prospects and hence for future consumption, which is exactly the intuition underlying the literature on habit formation models. In habit formation models (e.g., Campbell and Cochrane, 1999), the risk aversion of the representative agent varies with this difference between the consumption of the agent and a habit level formed through past consumption. Holding the habit level constant, a negative shock to consumption growth lowers the difference between consumption and the habit level, causing the agent to become more risk adverse. The opposite is true for a positive consumption growth shock. It follows that, consistent with our empirical results,

\footnotetext{
${ }^{13}$ This statement clearly depends on the magnitude of the reduction in the jump intensity. A substantial decrease in $\lambda$ does reduce the excess kurtosis of the SPD along with the standard deviation of the SPD.
} 
bad (good) news for bonds, which corresponds to good (bad) news for consumption growth, lowers (raises) aggregate risk aversion.

In summary, our empirical results suggest that macroeconomic announcements lead to changes in both the beliefs and preferences of market participants. On one hand, the observed decrease in the uncertainty implied by the SPD is consistent with market participants anticipating one less jump over a fixed horizon. On the other hand, the empirical correlations between the news content and the higher-order moments of the SPD indicate a change in risk aversion. Furthermore, the way the preferences of market participants change in response to the announcements agrees with the intuition underlying habit formation models.

\subsection{Model-Free Approach}

It is natural to wonder to what extent the interpretation of our empirical results offered above hinges on the specification of the jump diffusion model and on the calibrated parameter values. To address this issue, we alternatively consider the much more general framework of Bakshi et al. (2003) who characterize the link between the moments or the SPD, risk aversion, and the moments of the physical distribution. Specifically, they show that in power utility economies with aggregate relative risk aversion $\Gamma$, the risk-neutral skewness and kurtosis are linked to their physical counterparts by: ${ }^{14}$

$$
\begin{gathered}
\gamma_{1 n} \approx \bar{\gamma}_{1 n}-\Gamma \bar{\gamma}_{2 n} \bar{\sigma}_{n} \\
\gamma_{2 n} \approx \bar{\gamma}_{2 n}-\Gamma\left[2\left(\bar{\gamma}_{2 n}+5\right) \bar{\gamma}_{1 n}+\bar{\gamma}_{3 n}\right] \bar{\sigma}_{n}
\end{gathered}
$$

where $\bar{\sigma}_{n}, \bar{\gamma}_{1 n}, \bar{\gamma}_{2 n}$ and $\bar{\gamma}_{3 n}$ are the standard deviation, skewness, excess kurtosis, and fifth normalized moment of log returns under the physical probability measure, respectively.

Equation (29) shows immediately how a drop in risk aversion $\Gamma$ leads to a less negatively skewed and also less fat-tailed SPD. It also shows that in order to obtain the same effect through a change in the physical distribution, requires a strong correlation between the news content and the physical excess kurtosis $\bar{\gamma}_{2 n}$, such that bad news for bonds makes subsequent extreme price changes less likely. To check whether there is any evidence of such correlation in the data, we compute the excess kurtosis of daily returns for the months following the 25 most positive price changes and for the months following the 25 most negative price changes. The estimated excess kurtosis is 1.6 after large positive price changes and 2.5 after large negative price changes, suggesting that, if anything, bad news for bonds leads to an

\footnotetext{
${ }^{14}$ The power utility assumption is not critical. Bakshi et al. (2003) also generalize these results to a broader family of utility functions with possibly time-varying risk aversion.
} 
increase in the excess kurtosis of the physical distribution, rather than to a decrease. We therefore conclude that the much more general framework of Bakshi et al. (2003) confirms our earlier interpretation of our empirical results. Macroeconomic announcements lead to changes in both the beliefs and preferences of market participants.

\section{Conclusion}

We examined the effect of regularly scheduled macroeconomic announcements on the beliefs and preferences of participants in the U.S. Treasury market by comparing the option-implied SPD of bond prices shortly before and after the announcements. At least two stylized facts emerged from our empirical analysis. First, the announcements reduce the uncertainty implicit in the second moment of the SPD, regardless of the content of the news. Second, the changes in higher-order moments of the SPD depend on whether the news is good or bad. Specifically, bad news for bonds, which tends to be good news for economic prospects, leads to a less negatively skewed and also less fat-tailed SPD.

We used both a jump diffusion model and a model-free approach to interpret these results and, more importantly, to disentangle changes in beliefs and changes in preferences. The effect of the announcements on the second moments of the SPD is consistent with a drop in the jump intensity. The changes in the higher-order moments, however, cannot be attributed to variation in the price process. Instead, we show that the changes in the higherorder moments are consistent with time-varying risk aversion. Bad news for bonds leads market participants to become less risk averse and for the SPD to be more similar to the PDF. Since bad news for bonds tends to be good news for economic prospects, this variation in risk aversion is consistent with the intuition underlying habit formation models. 


\section{A Appendix}

\section{A.1 Gram-Charlier Density for Futures Options}

Recall the Gram-Charlier density function (11) and its components:

$$
f(\omega)=\varphi(\omega)-\frac{\gamma_{1 n}}{3 !} D^{3} \varphi(\omega)+\frac{\gamma_{2 n}}{4 !} D^{4} \varphi(\omega)
$$

with $\omega=\left(x_{t+1}^{n}-\mu_{n}\right) / \sigma_{n}$ and $\varphi(\omega)=(2 \pi)^{-1 / 2} \exp \left(-\omega^{2} / 2\right)$. Under risk-neutrality, the call option price depends on the conditional distribution of the standardized log price change $\omega$ :

$$
\begin{aligned}
\int_{\omega^{*}}^{\infty}\left(F_{t} \mathrm{e}^{\mu_{n}+\sigma_{n} \omega}-K\right) f(\omega) d \omega= & \int_{\omega^{*}}^{\infty}\left(F_{t} \mathrm{e}^{\mu_{n}+\sigma_{n} \omega}-K\right) \varphi(\omega) d \omega \\
& -\frac{\gamma_{1 n}}{3 !} \int_{\omega^{*}}^{\infty}\left(F_{t} \mathrm{e}^{\mu_{n}+\sigma_{n} \omega}-K\right) \varphi^{\prime \prime \prime}(\omega) d \omega \\
& +\frac{\gamma_{2 n}}{4 !} \int_{\omega^{*}}^{\infty}\left(F_{t} \mathrm{e}^{\mu_{n}+\sigma_{n} \omega}-K\right) \varphi^{\prime \prime \prime \prime}(\omega) d \omega \\
= & I_{1}-\frac{\gamma_{1 n}}{3 !} I_{2}+\frac{\gamma_{2 n}}{4 !} I_{3},
\end{aligned}
$$

with $\omega^{*}=\left(\log \left(K / F_{t}\right)-\mu_{n}\right) / \sigma_{n}$. The first term on the right side of this equality is the Black (1976) call option price capitalized to the end of the period:

$$
I_{1}=F_{t} \mathrm{~N}(d)-K \mathrm{~N}\left(d-\sigma_{n}\right) .
$$

For the second term, we obtain by repeated integration by parts and using the fact that $\lim _{x \rightarrow \infty} \mathrm{e}^{x} \varphi^{(n)}(x)=0$, the expression:

$$
I_{2}=-\sigma_{n} K \varphi\left(\omega^{*}\right)\left(\omega^{*}+\sigma_{n}\right)-\sigma_{n}^{3} I_{1}-\sigma_{n}^{3} K \mathrm{~N}\left(-\omega^{*}\right) .
$$

The third term is:

$$
I_{3}=\sigma_{n} K \varphi\left(\omega^{*}\right)\left[\left(\omega^{*}\right)^{2}-1+\omega^{*} \sigma_{n}+\sigma_{n}^{2}\right]+\sigma_{n}^{4} I_{1}+\sigma_{n}^{4} K \mathrm{~N}\left(-\omega^{*}\right) .
$$

The call option price is therefore:

$$
\begin{aligned}
C_{n t} & =\mathrm{e}^{-r_{n t} n}\left(I_{1}-\frac{\gamma_{1 n}}{3 !} I_{2}+\frac{\gamma_{2 n}}{4 !} I_{3}\right) \\
= & \mathrm{e}^{-r_{n t} n}\left[F_{t} \mathrm{~N}(d)-K \mathrm{~N}\left(d-\sigma_{n}\right)\right]\left(1+\frac{\gamma_{1 n}}{3 !} \sigma_{n}^{3}+\frac{\gamma_{2 n}}{4 !} \sigma_{n}^{4}\right) \\
& +\frac{\gamma_{1 n}}{3 !}\left[\mathrm{e}^{-r_{n t} n} \sigma_{n} K \varphi\left(\omega^{*}\right)\left(\omega^{*}+\sigma_{n}\right)+\mathrm{e}^{-r_{n t} n} \sigma_{n}^{3} K \mathrm{~N}\left(-\omega^{*}\right)\right] \\
& +\frac{\gamma_{2 n}}{4 !}\left[\mathrm{e}^{-r_{n t} n} \sigma_{n} K \varphi\left(\omega^{*}\right)\left[\left(\omega^{*}\right)^{2}-1+\omega^{*} \sigma_{n}+\sigma_{n}^{2}\right]+\mathrm{e}^{-r_{n t} n} \sigma_{n}^{4} K \mathrm{~N}\left(-\omega^{*}\right)\right] .
\end{aligned}
$$

Finally, we obtain equation (12) from equation (A.6) by (i) substituting the identities $\omega^{*}=\sigma_{n}-d$ and $F_{t} \varphi(d)=K \varphi\left(d-\sigma_{n}\right)$ (which is equivalent to $F_{t} \varphi(d)=K \varphi\left(\sigma_{n}-d\right)$ ), (ii) applying the arbitrage condition $\mu_{n}=-\sigma_{n}^{2} / 2-\sigma_{n}^{3} \gamma_{1 n} / 3$ ! $-\sigma_{n}^{4} \gamma_{2 n} / 4$ !, and (iii) eliminating 
the terms involving $\sigma_{n}^{3}$ and $\sigma_{n}^{4}$, which are very small (see Backus et al., 1997).

Consider now a linear approximation of the Black (1976) formula as a function of implied volatility $v_{n}$ around the point $v_{n}=\sigma_{n}$ :

$$
\begin{aligned}
C_{n t} & =\mathrm{e}^{-r_{n t} n}\left[F_{t} \mathrm{~N}\left[d\left(v_{n}\right)\right]-K \mathrm{~N}\left[d\left(v_{n}\right)-v_{n}\right]\right] \\
& \cong \mathrm{e}^{-r_{n t} n}\left[F_{t} \mathrm{~N}\left[d\left(\sigma_{n}\right)\right]-K \mathrm{~N}\left[d\left(\sigma_{n}\right)-\sigma_{n}\right]\right]+F_{t} \mathrm{e}^{-r_{n t} n} \varphi(d)\left(v-\sigma_{n}\right) .
\end{aligned}
$$

If we equate the approximated call option price in equation (A.7) to the Gram-Charlier call option price in equation (12), we obtain the implied volatility function in equation (14).

We briefly repeat the same steps for a put option:

$$
\begin{aligned}
\int_{-\infty}^{\omega^{*}}\left(K-F_{t} \mathrm{e}^{\mu_{n}+\sigma_{n} \omega}\right) f(\omega) d \omega & =\int_{-\infty}^{\omega^{*}}\left(K-F_{t} \mathrm{e}^{\mu_{n}+\sigma_{n} \omega}\right) \varphi(\omega) d \omega \\
& -\frac{\gamma_{1 n}}{3 !} \int_{-\infty}^{\omega^{*}}\left(K-F_{t} \mathrm{e}^{\mu_{n}+\sigma_{n} \omega}\right) \varphi^{\prime \prime \prime}(\omega) d \omega \\
& +\frac{\gamma_{2 n}}{4 !} \int_{-\infty}^{\omega^{*}}\left(K-F_{t} \mathrm{e}^{\mu_{n}+\sigma_{n} \omega}\right) \varphi^{\prime \prime \prime \prime}(\omega) d \omega \\
& =I_{4}-\frac{\gamma_{1 n}}{3 !} I_{5}+\frac{\gamma_{2 n}}{4 !} I_{6},
\end{aligned}
$$

with $\omega^{*}=\left(\log \left(K / F_{t}\right)-\mu_{n}\right) / \sigma_{n}$. Using the same logic as for the call option, we obtain:

$$
\begin{aligned}
& I_{4}=K \mathrm{~N}\left(\sigma_{n}-d\right)-F_{t} \mathrm{~N}(-d) \\
& I_{5}=\sigma_{n} K \varphi\left(\omega^{*}\right)\left(-\omega^{*}-\sigma_{n}\right)+\sigma_{n}^{3} K \mathrm{~N}\left(\omega^{*}\right) \\
& I_{6}=-\sigma_{n} K \varphi\left(\omega^{*}\right)\left(1-\left(\omega^{*}\right)^{2}-\sigma_{n} \omega^{*}-\sigma_{n}^{2}\right)-\sigma_{n}^{4} K \mathrm{~N}\left(\omega^{*}\right) .
\end{aligned}
$$

The put price is then:

$$
\begin{aligned}
P_{n t}= & \mathrm{e}^{-r_{n t} n}\left(I_{4}-\frac{\gamma_{1 n}}{3 !} I_{5}+\frac{\gamma_{2 n}}{4 !} I_{6}\right) \\
= & \mathrm{e}^{-r_{n t} n}\left[K \mathrm{~N}\left(\sigma_{n}-d\right)-F_{t} \mathrm{~N}(-d)\right] \\
& +\frac{\gamma_{1 n}}{3 !}\left[\mathrm{e}^{-r_{n t} n} \sigma_{n} K \varphi\left(\omega^{*}\right)\left(-\omega^{*}-\sigma_{n}\right)+\mathrm{e}^{-r_{n t} n} \sigma_{n}^{3} K \mathrm{~N}\left(\omega^{*}\right)\right] \\
& +\frac{\gamma_{2 n}}{4 !}\left[-\mathrm{e}^{-r_{n t} n} \sigma_{n} K \varphi\left(\omega^{*}\right)\left(1-\left(\omega^{*}\right)^{2}-\sigma_{n} \omega^{*}-\sigma_{n}^{2}\right)-\mathrm{e}^{-r_{n t} n} \sigma_{n}^{4} K \mathrm{~N}\left(\omega^{*}\right)\right] .
\end{aligned}
$$

Applying the same substitutions as for the call option formula and observing again that $\omega^{*}=\sigma_{n}-d$, we obtain the Gram-Charlier put option price:

$$
\begin{aligned}
P_{n t} \cong & \mathrm{e}^{-r_{n t} n}\left[K \mathrm{~N}\left(\sigma_{n}-d\right)-F_{t} \mathrm{~N}(-d)\right] \\
& +F_{t} \mathrm{e}^{-r_{n t} n} \varphi(d) \sigma_{n}\left[\frac{\gamma_{1 n}}{3 !}\left(-2 \sigma_{n}+d\right)-\frac{\gamma_{2 n}}{4 !}\left(1-d^{2}+3 d \sigma_{n}-3 \sigma_{n}^{2}\right)\right] .
\end{aligned}
$$

We obtain the put option implied volatility function, analogous to equation (14), by equating a linear approximation of the Black formula for the put option similar to equation 
(A.7), to the Gram-Charlier put option price in equation (A.11). The result is:

$$
v_{n}(d) \cong \sigma_{n}\left[1+\frac{\gamma_{1 n}}{3 !}\left(-2 \sigma_{n}+d\right)-\frac{\gamma_{2 n}}{4 !}\left(1-d^{2}+3 d \sigma_{n}-3 \sigma_{n}^{2}\right)\right] .
$$

\section{A.2 American-Style Option Pricing with Gram-Charlier Densities}

We integrate the upper and lower bounds for the American-style call option price defined in equation (17) with respect to the risk neutral density function given by the Gram-Charlier expansion. The upper bound is just the undiscounted value of a European-style call option derived in equation (12):

$$
\begin{aligned}
C_{n t}^{u} \cong & F_{t} \mathrm{~N}(d)-K \mathrm{~N}\left(d-\sigma_{n}\right) \\
& \quad+F_{t} \varphi(d) \sigma_{n}\left[\frac{\gamma_{1 n}}{3 !}\left(2 \sigma_{n}-d\right)-\frac{\gamma_{2 n}}{4 !}\left(1-d^{2}+2 d \sigma_{n}-2 \sigma_{n}^{2}-\sigma_{n}+d\right)\right] .
\end{aligned}
$$

The lower bound is the maximum between the price of the European-style call option, equation (12), and the intrinsic value of the option, that is the difference between the expected future terminal price and the strike price. Obtaining the intrinsic value for an option on a bond futures is straightforward:

$$
\begin{aligned}
\mathrm{E}_{t}\left[F_{t+n}\right]-K & =\int_{-\infty}^{\infty} F_{t} f(\omega) d \omega-K \\
& =\int_{-\infty}^{\infty} F_{t}\left(\varphi(\omega)-\frac{\gamma_{1 n}}{3 !} D^{3} \varphi(\omega)+\frac{\gamma_{2 n}}{4 !} D^{4} \varphi(\omega)\right) d \omega-K \\
& =F_{t}-K,
\end{aligned}
$$

and hence we get:

$$
C_{n t}^{l}=\max \left[\begin{array}{c}
F_{t}-K, F_{t} \mathrm{e}^{-r_{n t} n} \mathrm{~N}(d)-K \mathrm{e}^{-r_{n t} n} \mathrm{~N}\left(d-\sigma_{n}\right)+ \\
F_{t} \mathrm{e}^{-r_{n t} n} \varphi(d) \sigma_{n}\left[\frac{\gamma_{1 n}}{3 !}\left(2 \sigma_{n}-d\right)-\frac{\gamma_{2 n}}{4 !}\left(1-d^{2}+2 d \sigma_{n}-2 \sigma_{n}^{2}-\sigma_{n}+d\right)\right]
\end{array}\right] .
$$

The formula for the Gram-Charlier American-style call price is the weighted average of the upper and lower bound:

$$
\begin{aligned}
& C_{n t}^{*} \cong \lambda_{n} C_{n t}^{u}\left(F_{t}, K, r_{n t}, d ; \sigma_{n}, \gamma_{1 n}, \gamma_{2 n}\right) \\
& +\left(1-\lambda_{n}\right) C_{n t}^{l}\left(F_{t}, K, r_{n t}, d ; \sigma_{n}, \gamma_{1 n}, \gamma_{2 n}\right) \\
& =\lambda_{n}\left[\begin{array}{c}
F_{t} \mathrm{~N}(d)-K \mathrm{~N}\left(d-\sigma_{n}\right) \\
+F_{t} \varphi(d) \sigma_{n}\left[\frac{\gamma_{1 n}}{3 !}\left(2 \sigma_{n}-d\right)-\frac{\gamma_{2 n}}{4 !}\left(1-d^{2}+2 d \sigma_{n}-2 \sigma_{n}^{2}-\sigma_{n}+d\right)\right]
\end{array}\right]+
\end{aligned}
$$

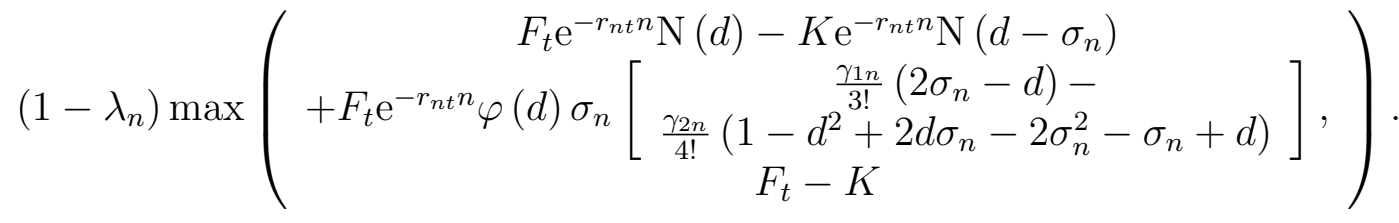


In the empirical implementation, we replace the max operator with a logistic approximation, to help in the non-linear optimization:

$$
\begin{aligned}
\operatorname{logit} \max [x, y] & =\frac{1}{1+\exp [-8(x-y)]} \\
\max [x, y] & \cong \operatorname{logit} \max [x, y] x+(1-\operatorname{logit} \max [x, y]) y .
\end{aligned}
$$

Melick and Thomas (1997) use a similar technique.

The American-style Gram-Charlier put option price can be obtained by analogous steps. 


\section{References}

Backus, David K., Silverio Foresi, Kai Li, and Liuren Wu, 1997, Accounting for biases in Black-Scholes, Working Paper, New York University.

Bakshi, Gurdip, Nikunj Kapadia, and Dilip Madan, 2003, Stock return characteristics, skew laws, and the differential pricing of individual equity options, Review of Financial Studies $16,101-143$.

Bates, David S., 2000, Post-' 87 crash fears in the S\&P 500 futures option market, Journal of Econometrics 94, 181-238.

Black, Fischer, and Myron S. Scholes, 1973, The Pricing of Options and Corporate Liabilities, Journal of Political Economy 81, 637-654.

Black, Fisher, 1976, The pricing of commodity contracts, Journal of Financial Economics $3,167-179$.

Bollerslev, Tim, Jun Cai, and Frank M. Song, 2000, Intraday periodicity, long memory volatility, and macroeconomic announcement effects in the U.S. Treasury bond market, Journal of Empirical Finance 7, 37-55.

Campbell, John Y., and John H. Cochrane, 1999, By force of habit: A consumption-based explanation of aggregate stock market behavior, Journal of Political Economy 107, 205251.

Chaudhary, Mohammed, and Jason Wei, 1994, Upper bounds for American futures options: A note, Journal of Futures Markets 14, 111-116.

Christoffersen, Peter, and Kris Jacobs, 2002, The importance of the loss function in option pricing, Working Paper, McGill University.

Ederington, Louis H., and Jae H. Lee, 1993, How markets process information: News releases and volatility, Journal of Finance 48, 1161-1191.

Ederington, Louis H., and Jae H. Lee, 1996, The creation and resolution of market uncertainty: The impact of information releases on implied volatility, Journal of Financial and Quantitative Analysis 31, 513-539.

Edison, Hali J., 1996, The reaction of exchange rates and interest rates to news releases, Working Paper, Board of Governors of the Federal Reserve System.

Engle, Robert F., and Joshua V. Rosenberg, 2002, Empirical pricing kernels, Journal of Financial Economics 64, 341-372.

Fleming, Michael J., and Eli M. Remolona, 1997, What moves the bond market?, Federal Reserve Bank of New York Economic Policy Review, 31-50.

Fleming, Michael J., and Eli M. Remolona, 1999, Price formation and liquidity in the U.S. Treasury market: The response to public information, Journal of Finance 54, 1901-1915. 
Hentschel, Ludger, 2002, Errors in implied volatility estimation, Journal of Financial and Quantitative Analysis, forthcoming.

Jarrow, Robert, and Andrew Rudd, 1982, Approximate valuation for arbitrary stochastic processes, Journal of Financial Economics 10, 347-369.

Jondeau, Eric, and Michael Rockinger, 2001, Gram-Charlier densities, Journal of Economic Dynamics and Control 25, 1457-1483.

Melick, William R., and Charles P. Thomas, 1997, Recovering an asset's implied SPD from option prices: An application to crude oil during the Gulf crisis, Journal of Financial and Quantitative Analysis 32, 91-115.

Merton, Robert C., 1976, Option pricing when underlying stock returns are discontinuous, Journal of Financial Economics 3, 125-144.

Naik, Vasanttilak, and Moon Lee, 1990, General equilibrium pricing of options on the market portfolio with discontinuous returns, Review of Financial Studies 3, 493-521. 


\section{Table 1: Announcement Timing}

Panel A shows the announcements, their abbreviations, the reported units of the variables, the times at which the announcements are normally released, and the number of times two announcements are concurrent (same date and time). Panel B shows the distribution of the announcements over the days of the week and the typical sequence of the announcements in a given month. The sample period is January 1995 through December 1999.

Panel A

\begin{tabular}{|c|c|c|c|c|c|c|c|c|c|c|c|c|c|}
\hline \multirow[b]{2}{*}{ Announcement } & \multirow[b]{2}{*}{ Abbrev. } & \multirow[b]{2}{*}{ Units } & \multirow{2}{*}{$\begin{array}{l}\text { Time } \\
\text { (ET) }\end{array}$} & \multicolumn{10}{|c|}{ Concurrent Announcements } \\
\hline & & & & 1 & 2 & 3 & 4 & 5 & 6 & 7 & 8 & 9 & 10 \\
\hline Consumer Price Index & CPI & $\%$ Change & $8: 30$ & 60 & 8 & 0 & 0 & 0 & 16 & 0 & 0 & 0 & 0 \\
\hline Housing Starts & HS & Millions of Units & $8: 30$ & & 59 & 0 & 0 & 1 & 0 & 0 & 0 & 0 & 0 \\
\hline Civilian Unemployment & CUR & $\%$ Level & $8: 30$ & & & 60 & 60 & 0 & 0 & 0 & 0 & 0 & 0 \\
\hline Nonfarm Payrolls & NFP & Thousands & $8: 30$ & & & & 60 & 0 & 0 & 0 & 0 & 0 & 0 \\
\hline Producer Price Index & PPI & $\%$ Change & $8: 30$ & & & & & 60 & 14 & 0 & 0 & 0 & 0 \\
\hline Retail Sales & $\mathrm{RS}$ & $\%$ Change & $8: 30$ & & & & & & 60 & 0 & 0 & 0 & 0 \\
\hline Industrial Production & IP & $\%$ Change & $9: 15$ & & & & & & & 60 & 0 & 0 & 0 \\
\hline Consumer Confidence & $\mathrm{CC}$ & $\%$ Level & $10: 00$ & & & & & & & & 60 & 2 & 0 \\
\hline NAPM index & NAPM & $\%$ Level & $10: 00$ & & & & & & & & & 60 & 0 \\
\hline FOMC Target & FOMC & $\%$ Rate & $14: 15$ & & & & & & & & & & 40 \\
\hline
\end{tabular}

Panel B

\begin{tabular}{|c|c|c|c|c|c|c|}
\hline & $\mathrm{M}$ & $\mathrm{T}$ & W & $\mathrm{T}$ & $\mathrm{F}$ & Sequence \\
\hline CPI & 0 & 22 & 14 & 14 & 10 & 8th \\
\hline HS & 0 & 21 & 17 & 11 & 10 & 4 th \\
\hline CUR & 0 & 0 & 0 & 3 & 57 & $3 \mathrm{rd}$ \\
\hline NFP & 0 & 0 & 0 & 3 & 57 & $3 \mathrm{rd}$ \\
\hline PPI & 0 & 6 & 11 & 14 & 29 & 6 th \\
\hline $\mathrm{RS}$ & 0 & 17 & 8 & 20 & 15 & 5 th \\
\hline IP & 4 & 15 & 12 & 8 & 21 & 7 th \\
\hline $\mathrm{CC}$ & 0 & 58 & 2 & 0 & 0 & $1 \mathrm{st}$ \\
\hline NAPM & 24 & 12 & 8 & 8 & 8 & 2nd \\
\hline FOMC & 0 & 28 & 11 & 1 & 0 & na \\
\hline
\end{tabular}




\section{Table 2: Implied Volatility}

This table shows the mean of the annualized volatility (in percent) implied by a binomial tree version of the Black (1976) formula, the standard deviation of the implied volatility, and the number of observations for each moneyness and time to maturity category. Moneyness is defined as $m=\ln (K / F) /\left(\sigma_{\text {atm }} \sqrt{T-t}\right)$.

\begin{tabular}{|c|c|c|c|c|c|c|c|c|c|}
\hline \multirow[b]{3}{*}{$m$} & \multicolumn{8}{|c|}{ Days to Maturity } & \multirow[b]{3}{*}{ Total } \\
\hline & \multicolumn{4}{|c|}{ Call Options } & \multicolumn{4}{|c|}{ Put Options } & \\
\hline & $8-30$ & $30-60$ & $60-180$ & $\geq 180$ & $8-30$ & $30-60$ & $60-180$ & $\geq 180$ & \\
\hline \multirow[t]{3}{*}{$<-2$} & 28.50 & 23.03 & 18.75 & 12.79 & 10.93 & 11.24 & 11.01 & 11.33 & 19.72 \\
\hline & $(9.38)$ & $(7.24)$ & $(6.65)$ & $(1.36)$ & $(2.48)$ & $(2.19)$ & $(1.56)$ & $(1.69)$ & $(10.75)$ \\
\hline & 16360 & 2774 & 507 & 10 & 6709 & 4654 & 5942 & 240 & 37196 \\
\hline \multirow[t]{3}{*}[-2,-1]{} & 9.33 & 9.82 & 10.10 & 10.64 & 9.61 & 9.80 & 9.87 & 10.04 & 9.72 \\
\hline & $(2.14)$ & $(1.41)$ & $(1.33)$ & $(1.56)$ & $(1.53)$ & $(1.49)$ & $(1.03)$ & $(0.98)$ & $(1.44)$ \\
\hline & 5456 & 1608 & 1247 & 25 & 45172 & 23878 & 29805 & 1139 & 108330 \\
\hline \multirow[t]{3}{*}[-1,0]{} & 8.72 & 9.08 & 9.26 & 9.42 & 9.17 & 9.26 & 9.45 & 9.60 & 9.18 \\
\hline & $(1.64)$ & $(1.09)$ & $(0.85)$ & $(0.90)$ & $(1.47)$ & $(1.21)$ & $(0.89)$ & $(0.78)$ & $(1.33)$ \\
\hline & 52414 & 17625 & 15956 & 254 & 146231 & 71262 & 71897 & 1919 & 377558 \\
\hline \multirow[t]{3}{*}[0,1]{} & 8.88 & 8.96 & 9.14 & 9.25 & 8.87 & 9.09 & 9.28 & 9.43 & 8.97 \\
\hline & $(1.37)$ & $(1.08)$ & $(0.84)$ & $(0.76)$ & $(1.59)$ & $(1.26)$ & $(0.85)$ & $(0.75)$ & $(1.23)$ \\
\hline & 152985 & 77513 & 81250 & 2084 & 40279 & 13876 & 11993 & 374 & 380354 \\
\hline \multirow[t]{3}{*}[1,2]{} & 9.13 & 9.23 & 9.37 & 9.22 & 9.49 & 9.19 & 9.54 & 9.65 & 9.24 \\
\hline & $(1.46)$ & $(1.36)$ & $(0.95)$ & $(0.84)$ & $(2.47)$ & $(1.62)$ & $(1.26)$ & $(0.96)$ & $(1.36)$ \\
\hline & 37746 & 19494 & 26909 & 983 & 3158 & 824 & 651 & 29 & 89794 \\
\hline \multirow[t]{3}{*}{$>2$} & 10.83 & 10.19 & 10.43 & 10.84 & 14.08 & 12.74 & 13.73 & 12.32 & 10.80 \\
\hline & $(2.43)$ & $(1.69)$ & $(1.47)$ & $(1.80)$ & $(7.08)$ & $(4.38)$ & $(3.65)$ & $(5.17)$ & $(2.75)$ \\
\hline & 4111 & 2602 & 3153 & 102 & 577 & 162 & 124 & 5 & 10836 \\
\hline \multirow[t]{3}{*}{ Total } & 10.12 & 9.38 & 9.28 & 9.32 & 9.27 & 9.43 & 9.62 & 9.83 & 9.57 \\
\hline & $(5.42)$ & $(2.63)$ & $(1.17)$ & $(0.92)$ & $(1.65)$ & $(1.42)$ & $(1.05)$ & $(1.05)$ & $(3.17)$ \\
\hline & 269072 & 121616 & 129022 & 3458 & 242126 & 114656 & 120412 & 3706 & 1004068 \\
\hline
\end{tabular}




\section{Table 3: Econometric Issues}

Panel A compares the annualized volatility $\sigma_{n}$, skewness $\gamma_{1 n}$, and excess kurtosis $\gamma_{2 n}$ of a GramCharlier expansion of the SPD estimated using either a least squares criterion for option prices or a least squares criterion for implied volatilities based on a linearization of the option pricing formula. Panel B compares the estimated moments of the SPD obtained either by treating the options as European style or by explicitly incorporating the American style early exercise feature. In all cases, the expansion of the SPD is either unconstrained or constrained to the positive domain. The results are based on a random sample of 3,000 options with 30, 60 and 90 days to maturity.

Panel A

\begin{tabular}{|c|c|c|c|c|c|}
\hline & & $\begin{array}{c}\text { Price Based } \\
\text { Unconstrained }\end{array}$ & $\begin{array}{l}\text { Price Based } \\
\text { Constrained }\end{array}$ & $\begin{array}{c}\text { Impl.Vol. Based } \\
\text { Unconstrained }\end{array}$ & $\begin{array}{c}\text { Impl.Vol. Based } \\
\text { Constrained }\end{array}$ \\
\hline \multirow[t]{3}{*}{30 Days } & $\begin{array}{c}\sigma_{n} \\
(\mathrm{se})\end{array}$ & $\begin{array}{c}0.092 \\
(0.001)\end{array}$ & $\begin{array}{c}0.092 \\
(0.001)\end{array}$ & $\begin{array}{c}0.092 \\
(0.001)\end{array}$ & $\begin{array}{c}0.092 \\
(0.001)\end{array}$ \\
\hline & $\begin{array}{l}\gamma_{1 n} \\
(\mathrm{se})\end{array}$ & $\begin{array}{l}-0.088 \\
(0.025)\end{array}$ & $\begin{array}{l}-0.088 \\
(0.025)\end{array}$ & $\begin{array}{l}-0.105 \\
(0.070)\end{array}$ & $\begin{array}{l}-0.105 \\
(0.070)\end{array}$ \\
\hline & $\begin{array}{l}\gamma_{2 n} \\
(\mathrm{se})\end{array}$ & $\begin{array}{l}1.363 \\
(0.070)\end{array}$ & $\begin{array}{l}1.363 \\
(0.070)\end{array}$ & $\begin{array}{l}1.211 \\
(0.121)\end{array}$ & $\begin{array}{c}1.211 \\
(0.121)\end{array}$ \\
\hline \multirow[t]{3}{*}{60 Days } & $\begin{array}{c}\sigma_{n} \\
\text { (se) }\end{array}$ & $\begin{array}{c}0.097 \\
(0.001)\end{array}$ & $\begin{array}{c}0.097 \\
(0.001)\end{array}$ & $\begin{array}{c}0.093 \\
(0.001)\end{array}$ & $\begin{array}{c}0.093 \\
(0.001)\end{array}$ \\
\hline & $\begin{array}{l}\gamma_{1 n} \\
\text { (se) }\end{array}$ & $\begin{array}{l}-0.182 \\
(0.017)\end{array}$ & $\begin{array}{l}-0.182 \\
(0.017)\end{array}$ & $\begin{array}{c}0.065 \\
(0.050)\end{array}$ & $\begin{array}{c}0.065 \\
(0.050)\end{array}$ \\
\hline & $\begin{array}{l}\gamma_{2 n} \\
(\mathrm{se})\end{array}$ & $\begin{array}{l}1.633 \\
(0.051)\end{array}$ & $\begin{array}{l}1.633 \\
(0.051)\end{array}$ & $\begin{array}{c}0.753 \\
(0.080)\end{array}$ & $\begin{array}{c}0.753 \\
(0.080)\end{array}$ \\
\hline \multirow[t]{3}{*}{90 Days } & $\begin{array}{l}\sigma_{n} \\
(\mathrm{se})\end{array}$ & $\begin{array}{c}0.102 \\
(0.001)\end{array}$ & $\begin{array}{c}0.102 \\
(0.001)\end{array}$ & $\begin{array}{c}0.099 \\
(0.001)\end{array}$ & $\begin{array}{c}0.099 \\
(0.001)\end{array}$ \\
\hline & $\begin{array}{l}\gamma_{1 n} \\
\text { (se) }\end{array}$ & $\begin{array}{l}-0.389 \\
(0.014)\end{array}$ & $\begin{array}{l}-0.389 \\
(0.014)\end{array}$ & $\begin{array}{l}-0.205 \\
(0.043)\end{array}$ & $\begin{array}{l}-0.205 \\
(0.043)\end{array}$ \\
\hline & $\begin{array}{l}\gamma_{2 n} \\
\text { (se) }\end{array}$ & $\begin{array}{l}1.877 \\
(0.041)\end{array}$ & $\begin{array}{l}1.877 \\
(0.041)\end{array}$ & $\begin{array}{l}1.125 \\
(0.074)\end{array}$ & $\begin{array}{l}1.125 \\
(0.074)\end{array}$ \\
\hline
\end{tabular}


Panel B

\begin{tabular}{|c|c|c|c|c|c|}
\hline & & $\begin{array}{c}\text { Price Based } \\
\text { European } \\
\text { Unconstrained }\end{array}$ & $\begin{array}{c}\text { Price Based } \\
\text { European } \\
\text { Constrained }\end{array}$ & $\begin{array}{c}\text { Price Based } \\
\text { American } \\
\text { Unconstrained }\end{array}$ & $\begin{array}{c}\text { Price Based } \\
\text { American } \\
\text { Constrained }\end{array}$ \\
\hline \multirow[t]{4}{*}{30 Days } & $\begin{array}{c}\sigma_{n} \\
(\mathrm{se})\end{array}$ & $\begin{array}{c}0.092 \\
(0.001)\end{array}$ & $\begin{array}{c}0.092 \\
(0.001)\end{array}$ & $\begin{array}{c}0.092 \\
(0.001)\end{array}$ & $\begin{array}{c}0.092 \\
(0.001)\end{array}$ \\
\hline & $\begin{array}{l}\gamma_{1 n} \\
(\mathrm{se})\end{array}$ & $\begin{array}{l}-0.087 \\
(0.025)\end{array}$ & $\begin{array}{l}-0.087 \\
(0.025)\end{array}$ & $\begin{array}{l}-0.087 \\
(0.035)\end{array}$ & $\begin{array}{l}-0.087 \\
(0.035)\end{array}$ \\
\hline & $\begin{array}{l}\gamma_{2 n} \\
(\mathrm{se})\end{array}$ & $\begin{array}{c}1.363 \\
(0.070)\end{array}$ & $\begin{array}{c}1.363 \\
(0.070)\end{array}$ & $\begin{array}{c}1.363 \\
(0.232)\end{array}$ & $\begin{array}{c}1.363 \\
(0.232)\end{array}$ \\
\hline & $\begin{array}{c}\lambda_{n} \\
\text { (se) }\end{array}$ & - & - & $\begin{array}{c}0.000 \\
(0.007)\end{array}$ & $\begin{array}{c}0.000 \\
(0.007)\end{array}$ \\
\hline \multirow[t]{4}{*}{60 Days } & $\begin{array}{c}\sigma_{n} \\
(\mathrm{se})\end{array}$ & $\begin{array}{c}0.097 \\
(0.001)\end{array}$ & $\begin{array}{c}0.097 \\
(0.001)\end{array}$ & $\begin{array}{c}0.096 \\
(0.001)\end{array}$ & $\begin{array}{c}0.096 \\
(0.001)\end{array}$ \\
\hline & $\begin{array}{l}\gamma_{1 n} \\
(\mathrm{se})\end{array}$ & $\begin{array}{c}-0.182 \\
(0.017)\end{array}$ & $\begin{array}{c}-0.182 \\
(0.017)\end{array}$ & $\begin{array}{c}-0.142 \\
(0.025)\end{array}$ & $\begin{array}{c}-0.142 \\
(0.025)\end{array}$ \\
\hline & $\begin{array}{l}\gamma_{2 n} \\
(\mathrm{se})\end{array}$ & $\begin{array}{c}1.633 \\
(0.051)\end{array}$ & $\begin{array}{c}1.633 \\
(0.051)\end{array}$ & $\begin{array}{c}1.580 \\
(0.150)\end{array}$ & $\begin{array}{c}1.580 \\
(0.150)\end{array}$ \\
\hline & $\begin{array}{c}\lambda_{n} \\
(\mathrm{se})\end{array}$ & - & - & $\begin{array}{c}0.000 \\
(0.005)\end{array}$ & $\begin{array}{c}0.000 \\
(0.005)\end{array}$ \\
\hline \multirow[t]{4}{*}{90 Days } & $\begin{array}{c}\sigma_{n} \\
(\mathrm{se})\end{array}$ & $\begin{array}{c}0.102 \\
(0.001)\end{array}$ & $\begin{array}{c}0.102 \\
(0.001)\end{array}$ & $\begin{array}{c}0.102 \\
(0.001)\end{array}$ & $\begin{array}{c}0.102 \\
(0.001)\end{array}$ \\
\hline & $\begin{array}{l}\gamma_{1 n} \\
(\mathrm{se})\end{array}$ & $\begin{array}{l}-0.389 \\
(0.014)\end{array}$ & $\begin{array}{l}-0.389 \\
(0.014)\end{array}$ & $\begin{array}{l}-0.389 \\
(0.019)\end{array}$ & $\begin{array}{c}-0.389 \\
(0.019)\end{array}$ \\
\hline & $\begin{array}{l}\gamma_{2 n} \\
(\mathrm{se})\end{array}$ & $\begin{array}{c}1.877 \\
(0.041)\end{array}$ & $\begin{array}{c}1.877 \\
(0.041)\end{array}$ & $\begin{array}{c}1.877 \\
(0.125)\end{array}$ & $\begin{array}{c}1.877 \\
(0.125)\end{array}$ \\
\hline & $\begin{array}{c}\lambda_{n} \\
(\mathrm{se})\end{array}$ & - & - & $\begin{array}{c}0.000 \\
(0.004)\end{array}$ & $\begin{array}{c}0.000 \\
(0.004)\end{array}$ \\
\hline
\end{tabular}




\section{Table 4: Daily Effects of the Announcement}

This table shows selected parameter estimates for the following regression:

$$
\mu_{t}-\mu_{t-1}=\alpha_{t}+\sum_{k=1}^{9} \beta_{k t} D_{k t}+\gamma_{t} T+e_{t} .
$$

In Panel $\mathrm{A}, \mu_{t}$ is the average at-the-money implied volatility on day $t$. In Panel $\mathrm{B}$, it is the second moment $\sigma_{n}$, absolute value of skewness $\operatorname{abs}\left(\gamma_{1 n}\right)$, or excess kurtosis $\gamma_{2 n}$ of the SPD. $D_{k t}$ is a dummy variance indicating whether announcement $k$ occurs on day $t$ and $T$ is the maturity of the options.

Panel A

\begin{tabular}{|c|c|c|c|c|c|}
\hline & $\alpha$ & $\beta_{C P I}$ & $\beta_{E R}$ & $\beta_{P P I}$ & $R^{2}$ \\
\hline$v_{n}$ & -0.004 & $-0.266^{* * *}$ & $-0.845^{* * *}$ & $-0.279^{* * *}$ & 0.265 \\
\hline \multicolumn{6}{|c|}{ Panel B } \\
\hline & $\alpha$ & $\beta_{C P I}$ & $\beta_{E R}$ & $\beta_{P P I}$ & $R^{2}$ \\
\hline$\sigma_{n}$ & 0.053 & $-0.398^{* * *}$ & $-0.997^{* * *}$ & $-0.283^{* * *}$ & 0.235 \\
\hline $\operatorname{abs}\left(\gamma_{1 n}\right)$ & 0.021 & -0.000 & $-0.043^{*}$ & 0.036 & 0.026 \\
\hline$\gamma_{2 n}$ & 0.030 & 0.039 & 0.065 & 0.103 & 0.019 \\
\hline
\end{tabular}

$*, * *$, and $* * *$ denote statistical significance at the one, five, and 10 percent levels, respectively. Significance levels do not change if heteroscedasticity corrected standard errors are used. 


\section{Table 5: Intradaily Effects of the Announcement}

This table shows selected parameter estimates for the following regression:

$$
\mu_{\text {post }}-\mu_{\text {pre }}=\alpha_{t}+\sum_{k=1}^{9} \beta_{k t} D_{k t}+\gamma_{t} T+e_{t} .
$$

In Panel $\mathrm{A}, \mu_{\text {pre }}$ and $\mu_{\text {post }}$ are the average at-the-money implied volatility during the 45 minutes before and after the release, respectively. In Panel B, they are the second moment $\sigma_{n}$, absolute value of skewness abs $\left(\gamma_{1 n}\right)$, or excess kurtosis $\gamma_{2 n}$ of the corresponding SPDs. $D_{k t}$ is a dummy variance indicating whether announcement $k$ occurs on day $t$ and $T$ is the maturity of the options.

Panel A

\begin{tabular}{|c|c|c|c|c|c|}
\hline & $\alpha$ & $\beta_{C P I}$ & $\beta_{E R}$ & $\beta_{P P I}$ & $R^{2}$ \\
\hline$v_{n}$ & 0.024 & $-0.225^{* * *}$ & $-0.815^{* * *}$ & $-0.320^{* * *}$ & 0.326 \\
\hline \multicolumn{6}{|c|}{ Panel B } \\
\hline & $\alpha$ & $\beta_{C P I}$ & $\beta_{E R}$ & $\beta_{P P I}$ & $R^{2}$ \\
\hline$\sigma_{n}$ & 0.036 & $-0.254^{* * *}$ & $-0.918^{* * *}$ & $-0.461^{* * *}$ & 0.184 \\
\hline $\operatorname{abs}\left(\gamma_{1 n}\right)$ & -0.008 & 0.010 & -0.017 & -0.002 & 0.008 \\
\hline$\gamma_{2 n}$ & 0.135 & 0.263 & 0.083 & 0.153 & 0.019 \\
\hline
\end{tabular}

$*, * *$, and $* * *$ denote statistical significance at the one, five, and 10 percent levels, respectively. Significance levels do not change if heteroscedasticity corrected standard errors are used. 


\section{Table 6: Daily Effect of the Information Content}

This table shows selected parameter estimates for the following regression:

$$
\mu_{t}-\mu_{t-1}=\alpha_{k}+\beta_{k} S_{k}+\sum_{h=1}^{H} \delta_{h} S_{h}+\gamma_{k} T+e_{k} .
$$

In Panel $\mathrm{A}, \mu_{t}$ is the average at-the-money implied volatility on day $t$. In Panel $\mathrm{B}$, it is the second moment $\sigma_{n}$, skewness $\gamma_{1 n}$, or excess kurtosis $\gamma_{2 n}$ of the SPD. $S$ denotes the standardized announcement surprise, $h$ enumerates announcements which are released concurrently with announcement $k$, and $T$ is the maturity of the options.

\section{Panel A}

\begin{tabular}{cccc}
\hline & \multicolumn{3}{c}{$v_{n}$} \\
\cline { 2 - 4 } & $\alpha_{k}$ & $\beta_{k}$ & $R^{2}$ \\
\hline CPI & $-0.981^{* * *}$ & 0.057 & 0.238 \\
NFP & $-1.242^{* * *}$ & 0.063 & 0.211 \\
PPI & $-0.662^{* * *}$ & 0.023 & 0.150 \\
\hline
\end{tabular}

Panel B

\begin{tabular}{|c|c|c|c|c|c|c|c|c|c|}
\hline & \multicolumn{3}{|c|}{$\sigma_{n}$} & \multicolumn{3}{|c|}{$\gamma_{1 n}$} & \multicolumn{3}{|c|}{$\gamma_{2 n}$} \\
\hline & $\alpha_{k}$ & $\beta_{k}$ & $R^{2}$ & $\alpha_{k}$ & $\beta_{k}$ & $R^{2}$ & $\alpha_{k}$ & $\beta_{k}$ & $R^{2}$ \\
\hline CPI & $-1.752^{* * *}$ & -0.024 & 0.405 & 0.023 & $0.048^{* *}$ & 0.233 & -0.067 & $-0.193^{* *}$ & 0.276 \\
\hline NFP & $-1.257^{* * *}$ & -0.020 & 0.149 & 0.020 & $0.034^{*}$ & 0.087 & 0.087 & $-0.122^{*}$ & 0.122 \\
\hline PPI & $-0.482^{* *}$ & 0.139 & 0.053 & -0.043 & -0.016 & 0.020 & 0.038 & 0.057 & 0.059 \\
\hline
\end{tabular}

$*, * *$, and $* * *$ denote statistical significance at the one, five, and 10 percent levels, respectively. Significance levels do not change if heteroscedasticity corrected standard errors are used. 


\section{Table 7: Daily Effect of Good and Bad News}

This table shows selected parameter estimates for the following regression:

$$
\mu_{t}-\mu_{t-1}=\alpha_{k}+\left\{\begin{array}{l}
\beta_{G k}\left|S_{k}\right| \\
\beta_{B k}\left|S_{k}\right|
\end{array}+\sum_{h=1}^{H}\left\{\begin{array}{l}
\delta_{G h}\left|S_{h}\right| \\
\delta_{B h}\left|S_{h}\right|
\end{array}+\gamma_{k} T+e_{k} .\right.\right.
$$

In Panel $\mathrm{A}, \mu_{t}$ is the average at-the-money implied volatility on day $t$. In Panel $\mathrm{B}$, it is the second moment $\sigma_{n}$, skewness $\gamma_{1 n}$, or excess kurtosis $\gamma_{2 n}$ of the SPD. $S$ denotes the standardized announcement surprise, $h$ enumerates announcements which are released concurrently with announcement $k$, and $T$ is the maturity of the options.

Panel A

\begin{tabular}{rrrrr}
\hline & \multicolumn{4}{c}{$v_{n}$} \\
\cline { 2 - 5 }$\alpha_{k}$ & \multicolumn{1}{c}{$\beta_{G k}$} & \multicolumn{1}{c}{$\beta_{B k}$} & \multicolumn{1}{c}{$R^{2}$} \\
\hline CPI & $-1.039^{* * *}$ & 0.029 & $0.171^{* *}$ & 0.319 \\
NFP & $-1.531^{* * *}$ & 0.102 & $0.369^{* * *}$ & 0.372 \\
PPI & $-0.726^{* * *}$ & -0.021 & 0.026 & 0.158 \\
\hline
\end{tabular}

Panel B

\begin{tabular}{|c|c|c|c|c|c|c|c|c|c|c|c|c|}
\hline & \multicolumn{4}{|c|}{$\sigma_{n}$} & \multicolumn{4}{|c|}{$\gamma_{1 n}$} & \multicolumn{4}{|c|}{$\gamma_{2 n}$} \\
\hline & $\alpha_{k}$ & $\beta_{G k}$ & $\beta_{B k}$ & $R^{2}$ & $\alpha_{k}$ & $\beta_{G k}$ & $\beta_{B k}$ & $R^{2}$ & $\alpha_{k}$ & $\beta_{G k}$ & $\beta_{B k}$ & $R^{2}$ \\
\hline CPI & $-1.826^{* * *}$ & ${ }^{*} 0.143$ & 0.109 & 0.459 & 0.023 & -0.035 & $0.097^{* *}$ & 0.254 & -0.079 & 0.104 & $-0.238^{* *}$ & 0.331 \\
\hline NFP & $-1.487^{* * *}$ & ${ }^{k} 0.191$ & 0.224 & 0.186 & -0.087 & 0.034 & $0.087^{* *}$ & 0.169 & 0.043 & -0.103 & $-0.356^{* *}$ & 0.184 \\
\hline PPI & $-0.643^{* *}$ & -0.309 & -0.203 & 0.129 & -0.040 & $0.141^{*}$ & $0.136^{*}$ & 0.103 & 0.038 & $-0.364^{* *}$ & * $-0.353^{* *}$ & 0.171 \\
\hline
\end{tabular}

$*, * *$, and $* * *$ denote statistical significance at the one, five, and 10 percent levels, respectively. Significance levels do not change if heteroscedasticity corrected standard errors are used. 


\section{Table 8: Intradaily Effect of the Information Content}

This table shows selected parameter estimates for the following regression:

$$
\mu_{\text {post }}-\mu_{\text {pre }}=\alpha_{k}+\beta_{k} S_{k}+\sum_{h=1}^{H} \delta_{h} S_{h}+\gamma_{k} T+e_{k} .
$$

In Panel $\mathrm{A}, \mu_{\text {pre }}$ and $\mu_{\text {post }}$ are the average at-the-money implied volatility during the 45 minutes before and after the release, respectively. In Panel B, they are the second moment $\sigma_{n}$, skewness $\gamma_{1 n}$, or excess kurtosis $\gamma_{2 n}$ of the corresponding SPDs. $S$ denotes the standardized announcement surprise, $h$ enumerates announcements which are released concurrently with announcement $k$, and $T$ is the maturity of the options.

Panel A

\begin{tabular}{cccc}
\hline & \multicolumn{3}{c}{$v_{n}$} \\
\cline { 2 - 4 } & \multicolumn{1}{c}{$\alpha_{k}$} & $\beta_{k}$ & $R^{2}$ \\
\hline CPI & $-0.530^{* *}$ & 0.063 & 0.158 \\
NFP & $-0.884^{* * *}$ & 0.075 & 0.128 \\
PPI & $-0.409^{* *}$ & 0.042 & 0.136 \\
\hline
\end{tabular}

Panel B

\begin{tabular}{|c|c|c|c|c|c|c|c|c|c|}
\hline & \multicolumn{3}{|c|}{$\sigma_{n}$} & \multicolumn{3}{|c|}{$\gamma_{1 n}$} & \multicolumn{3}{|c|}{$\gamma_{2 n}$} \\
\hline & $\alpha_{k}$ & $\beta_{k}$ & $R^{2}$ & $\alpha_{k}$ & $\beta_{k}$ & $R^{2}$ & $\alpha_{k}$ & $\beta_{k}$ & $R^{2}$ \\
\hline CPI & $-0.410^{* *}$ & -0.028 & 0.081 & -0.031 & $0.064^{* *}$ & 0.081 & 0.137 & $-0.179^{*}$ & 0.077 \\
\hline NFP & $-0.912^{* * *}$ & ${ }^{*}-0.076$ & 0.124 & 0.073 & $0.073^{* *}$ & 0.104 & 0.085 & $-0.262^{* *}$ & 0.115 \\
\hline PPI & $-0.290^{* *}$ & -0.016 & 0.032 & -0.048 & $0.074^{*}$ & 0.066 & 0.239 & $-0.190^{*}$ & 0.050 \\
\hline
\end{tabular}

$*, * *$, and $* * *$ denote statistical significance at the one, five, and 10 percent levels, respectively. Significance levels do not change if heteroscedasticity corrected standard errors are used. 


\section{Table 9: The Intradaily Effect of Good and Bad News}

This table shows selected parameter estimates for the following regression:

$$
\mu_{\text {post }}-\mu_{\text {pre }}=\alpha_{k}+\left\{\begin{array}{l}
\beta_{G k}\left|S_{k}\right| \\
\beta_{B k}\left|S_{k}\right|
\end{array}+\sum_{h=1}^{H}\left\{\begin{array}{l}
\delta_{G h}\left|S_{h}\right| \\
\delta_{B h}\left|S_{h}\right|
\end{array}+\gamma_{k} T+e_{k} .\right.\right.
$$

In Panel $\mathrm{A}, \mu_{\text {pre }}$ and $\mu_{\text {post }}$ are the average at-the-money implied volatility during the 45 minutes before and after the release, respectively. In Panel B, they are the second moment $\sigma_{n}$, skewness $\gamma_{1 n}$, or excess kurtosis $\gamma_{2 n}$ of the corresponding SPDs. $S$ denotes the standardized announcement surprise, $h$ enumerates announcements which are released concurrently with announcement $k$, and $T$ is the maturity of the options.

Panel A

\begin{tabular}{ccccc}
\hline & \multicolumn{4}{c}{$v_{n}$} \\
\cline { 2 - 5 } & \multicolumn{1}{c}{$\alpha_{k}$} & $\beta_{G k}$ & $\beta_{B k}$ & \multicolumn{1}{c}{$R^{2}$} \\
\hline CPI & $-0.556^{* *}$ & -0.039 & $0.122^{*}$ & 0.206 \\
NFP & $-1.093^{* * *}$ & 0.105 & $0.267^{* *}$ & 0.223 \\
PPI & $-0.477^{* *}$ & -0.042 & 0.038 & 0.151 \\
\hline
\end{tabular}

Panel B

\begin{tabular}{|c|c|c|c|c|c|c|c|c|c|c|c|c|}
\hline & \multicolumn{4}{|c|}{$\sigma_{n}$} & \multicolumn{4}{|c|}{$\gamma_{1 n}$} & \multicolumn{4}{|c|}{$\gamma_{2 n}$} \\
\hline & $\alpha_{k}$ & $\beta_{G k}$ & $\beta_{B k}$ & $R^{2}$ & $\alpha_{k}$ & $\beta_{G k}$ & $\beta_{B k}$ & $R^{2}$ & $\alpha_{k}$ & $\beta_{G k}$ & $\beta_{B k}$ & $R^{2}$ \\
\hline CPI & $-0.542^{* *}$ & -0.008 & -0.049 & 0.142 & -0.033 & 0.080 & $0.109^{* *}$ & 0.098 & 0.164 & -0.074 & $-0.412^{* *}$ & 0.097 \\
\hline NFP & $-1.167^{* * *}$ & 0.035 & 0.007 & 0.179 & 0.068 & -0.011 & $0.140^{* *}$ & 0.145 & 0.021 & -0.009 & $-0.556^{* * *}$ & 0.164 \\
\hline PPI & $-0.382^{* *}$ & -0.112 & -0.107 & 0.106 & -0.091 & $0.173^{* *}$ & $0.289^{* * *}$ & 0.174 & 0.047 & $-0.232^{*}$ & * $-0.790^{* * *}$ & 0.107 \\
\hline
\end{tabular}

$*, * *$, and $* * *$ denote statistical significance at the one, five, and 10 percent levels, respectively. Significance levels do not change if heteroscedasticity corrected standard errors are used. 
Figure 1: Implied Volatility Surface

This figure plots the implied volatility of U.S. Treasury bond futures options from 1995 to 1999 as a function of time to maturity and moneyness. Implied volatilities are computed by inverting a binomial tree version of the Black (1976) formula and are smoothed using a two-dimensional kernel regression. Moneyness is defined as $m=\ln (K / F) /\left(\sigma_{\text {atm }} \sqrt{T-t}\right)$.

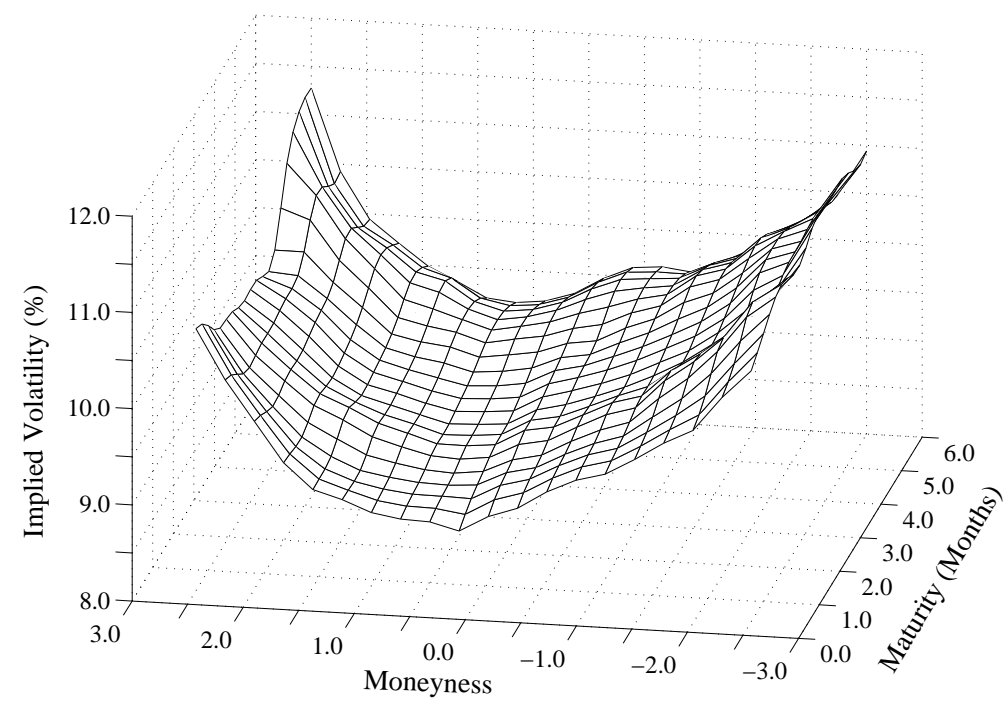


Figure 2: Day of the Week and Time of the Day Effects

This figure plots the average at-the-money implied volatility (circles) as well as the standard deviation (crosses), skewness (triangles), and excess kurtosis (squares) of the option-implied SPD for different days of the week and different times of the day.
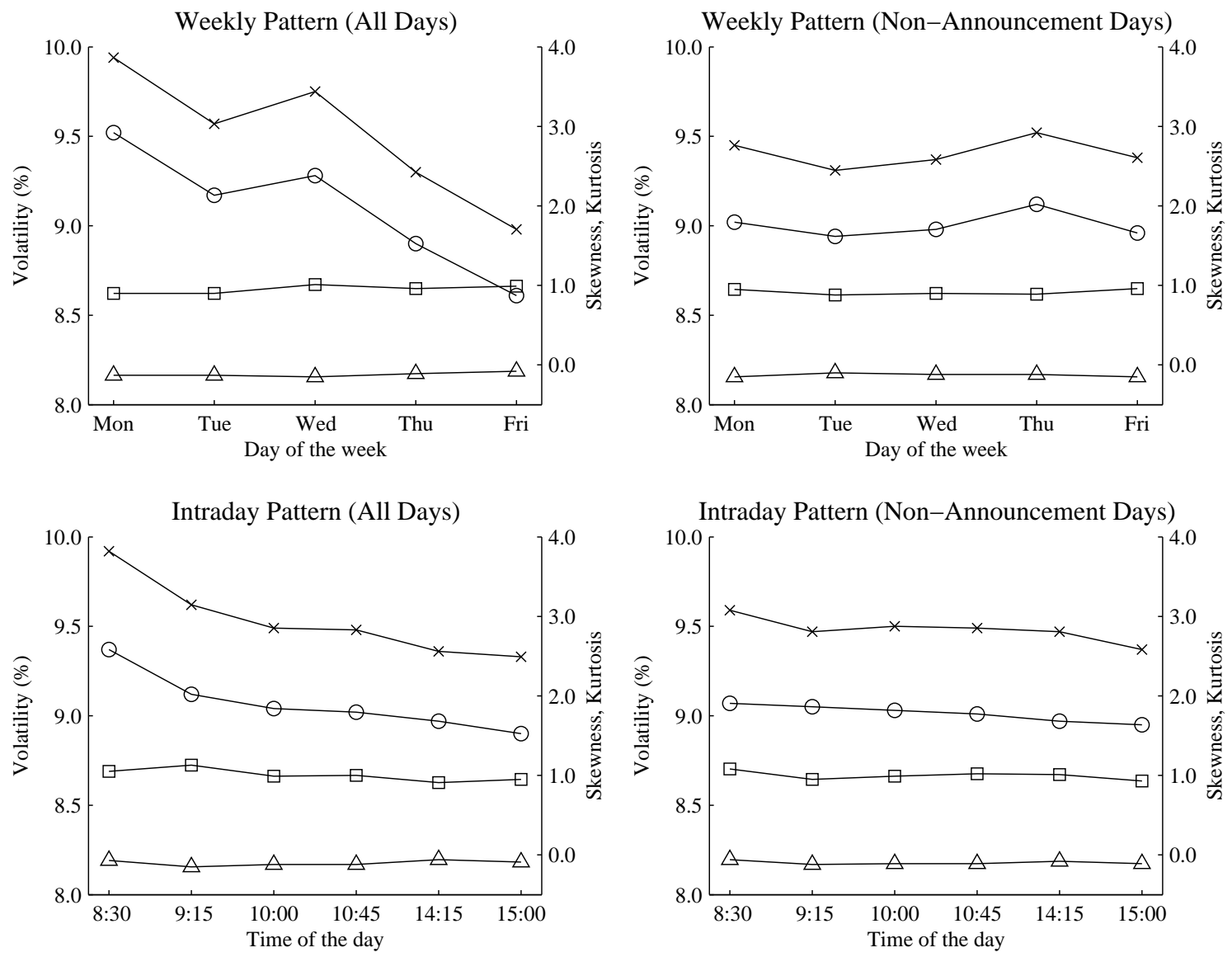


\section{Figure 3: Jump-Diffusion Simulated Patterns}

The top left plot shows the relationship between the implied volatility and moneyness for a jumpdiffusion model with jump-intensity $\lambda=5$ (continuous line) or $\lambda=4$ (crossed line) and with constant relative risk aversion $\Gamma=5$. The top right plot shows the effect of changing risk aversion from $\Gamma=10$ (continuous line) to $\Gamma=1$ (crossed line) with a jump-intensity of $\lambda=5$. The bottom plot shows the relationships between the skewness (triangles) or excess kurtosis (circles) of the option-implied SPD and risk aversion $\Gamma$ with a jump-intensity of $\lambda=5$.
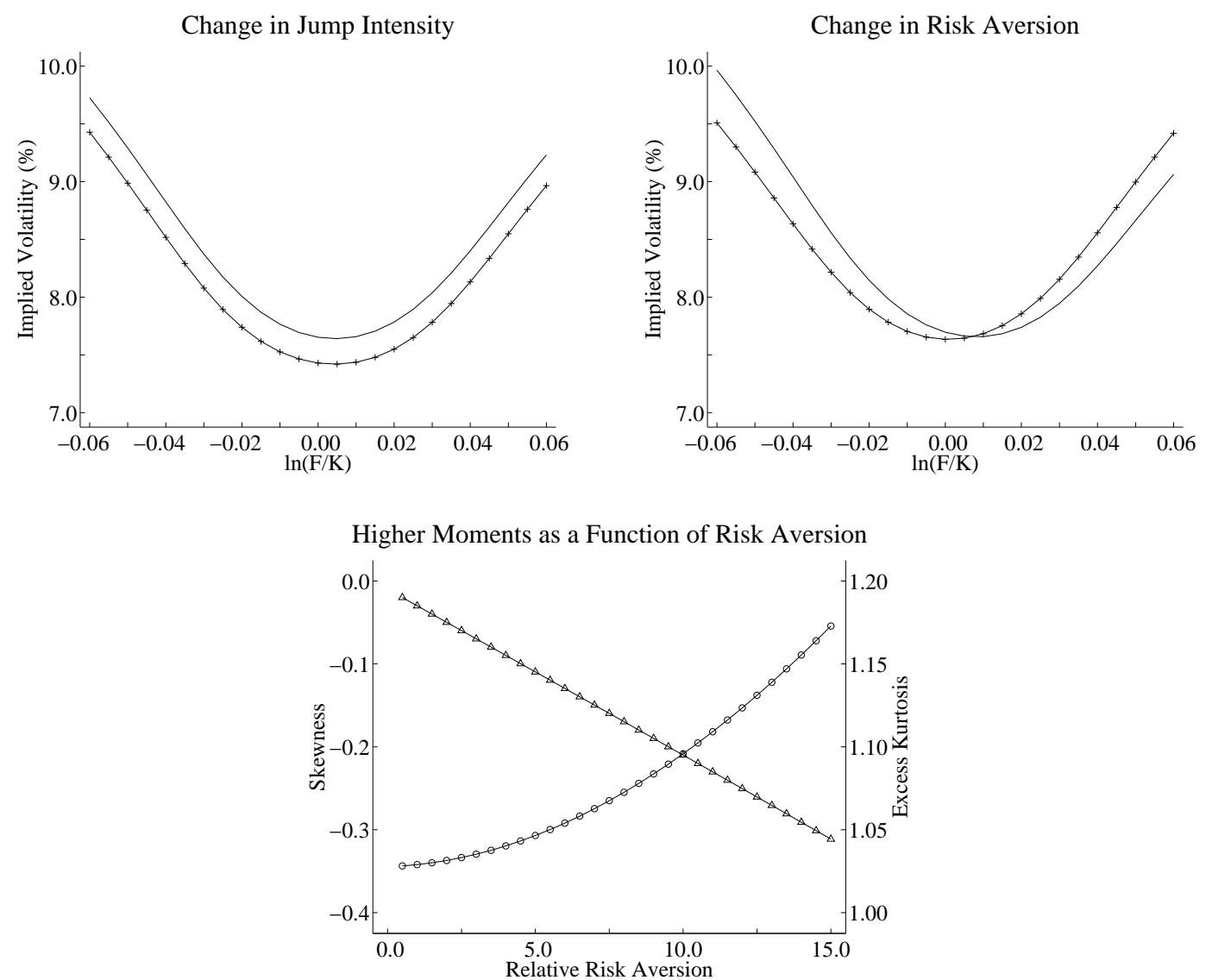